\title{
PHOTODIMERIZATION IN THE SOLID STATE
}

\author{
G. M. J. SCHMIDT \\ Department of Chemistry, Weizmann Institute of Science, \\ Rehovot, Israel
}

\begin{abstract}
Following a brief historical review of solid-state photochemistry current research is discussed under four parallel headings: first, analysis of the topochemical postulate according to which the course of the solid-state reaction and the stereochemistry of the photodimer (if any) can be predicted from the configuration and nearest-neighbour geometry of closest monomer molecules in the crystal lattice; secondly, the study of the locus of the reaction, that is the dependence of the course of the reaction or (dimerization, cis $\rightarrow$ trans isomerization) on crystal texture (dislocation, grain and phase boundaries); thirdly, a better understanding of the packing principles of organic molecules in their crystal structure to enable us to construct photoreactive (or lightstable) crystal structures of any given monomer as well as mixed crystals of potentially codimerizable monomers for synthetic purposes or energy-transfer studies.

Several approaches to this problem of 'crystal engineering' based on generalizations of packing modes of primary amides and of dichlorophenyl derivatives are outlined, and their application to a systematic photochemistry of the solid state discussed.
\end{abstract}

\section{INTRODUCTION}

Thermal reactions of organic compounds in the solid state are nearly as old as organic chemistry itself. Light-induced reactions such as the photodimerization of solid cinnamic acids, the reversible photochromy of the anils of salicylaldehyde, fulgides, tetrachloronaphthoquinone, and other solid-state reactions were already being studied towards the end of the last and the beginning of this century, by Marckwald ${ }^{1}$, Ciamician and Silber ${ }^{2}$, Stobbe $^{3}$, de Jong ${ }^{4}$, Senier ${ }^{5}$, to mention but a few. By the end of the nineteentwenties this phase of solid-state chemistry, which I would call the heroic era, had come to an end ${ }^{6}$, mainly because physical methods for the description of the solid state were as yet unable to provide insight into the molecular structure of organic solids. Thus, optical crystallography of organic compounds, by then a well established discipline which had passed through an intensive descriptive phase, had not progressed beyond the recognition of structural types in organic chemistry ${ }^{7}$. Treatment of the phenomena of polymorphism and phase transformation had not yet moved from the thermodynamic to the molecular stage. Solid-state chemists and crystallographers of the mid-twenties shared the belief that the phenomena which they were investigating, surely depended upon molecular packing arrangement; some expressed the hope that the novel technique of $x$-ray structure analysis would provide new impetus to their work. 


\section{G. M. J. SCHMIDT}

Certain general concepts had nevertheless been formulated already: thus, de Jong postulated in $1923^{4}$ that the two known crystal modifications of trans-cinnamic acid comprised identical molecules arranged differently in space, and the stereo-structure of the two photoproducts, $\alpha$-truxillic and $\beta$-truxinic acids, was directly related to the packing geometry of the monomer units in the two crystal structures from which the dimers were derived.

In assessing the more recent history of research on solid-state photochemistry one can, I believe, discern at least four concurrent and connected phases; the first has seen the experimental correlation of crystal structure on the one hand with photo-activity (or -stability) and product structure on the other ${ }^{8,9}$. We may call this the phase of the topochemical principle.

The second phase now actively investigated is concerned with the limits of this topochemical correlation of physical structure and chemical behaviour, particularly in the simple equation of physical structure with the crystal lattice as seen by the normal method of $\mathrm{x}$-ray structure analysis. The effect of crystal texture, e.g. disclocations ${ }^{10-12}$, is the major trend of this phase. We may call this the phase of the locus of the solid-state reaction. The present status of these two phases of solid-state research has provided the basis for the broad generalization that sophisticated solid-state techniques can define the initial state of the photochemical reaction, i.e. the conformation of the photoreactant in its ground state as well as the structure of the rigid matrix surrounding the reactant.

The third and fourth phases are in their infancy; in my view they must aim at the systematic development of solid-state photochemistry as a synthetic tool and as a methodology for the study of the mechanisms of photochemical reactions. To this end organic solid-state chemistry must be placed on a firmer basis. In an earlier review ${ }^{8}$ we emphasized the point that the rule of homology which has been essential to the development of solution chemistry does not hold in solid-state chemistry: "the reactions of homologous compounds, $\mathbf{R}^{\prime}\left(\mathrm{CH}_{2}\right)_{n} \mathbf{R}^{\prime \prime}, \mathbf{R H a l}, \mathbf{R}^{-}$metal $^{+}$are not necessarily identical for all values of $n$, or for $\mathrm{Cl}, \mathrm{Br}$ etc., or for $\mathrm{Na}^{+}, \mathrm{K}^{+}$etc. Since solid-state reactions are controlled by the molecular packing arrangement which is sensitive to $n$, to the size of the substituent, to the coordination requirements of the cation (to mention but a few factors affecting the structure of organic crystals); generalizations based on one or two representatives of a homologous series can be highly misleading.'

The systematic development of our subject will be difficult if not impossible until we understand the intermolecular forces responsible for the stability of the crystalline lattice of organic compounds; a theory of the organic solid state is a requirement for the eventual control of molecular packing arrangement. Once such a theory exists we shall, in the present context of synthetic and mechanistic photochemistry, be able to 'engineer' crystal structures having intermolecular contact geometry appropriate for chemical reaction, much as, in other contexts, we shall construct organic conductors, catalysts, etc. In short, any rational development of the physics and chemistry of the solid state must be based upon a theory of molecular packing; since the molecules studied are complex, the theory will most likely be empirical for some time yet. Rules are now becoming available ${ }^{13-16}$ in what I would regard as phase three, the phase of crystal engineering. 
Given the observation that double bonds separated by a translation axis of $4 \AA$ can undergo cyclodimerization one might want to construct crystal structures in which this $4 \AA$ axis is predictably achieved for as large a class of unsaturated compounds as possible. A technique which could impose this $\beta$-type packing (or any other specified packing arrangement) by means of a simple chemical modification without affecting the photochemical process would be such a desirable goal. It would stimulate phase four, the phase of systematic solid-state photochemistry.

Once the solid-state chemist has the tools with which to control molecular packing arrangements he will be able to follow new lines of experimentation which so far have been largely denied to him. He will construct twocomponent single-phase systems of definable structure such as substitutional solid solutions; thus, experiments on energy transfer in the undisturbed crystal structure, so far confined to transfer between normal and deuterated molecules, the classical example of the use of solid solutions in photochemical work $^{17}$, will be extended, both for mechanistic and synthetic purposes, to molecules of greater variation. In this manner experiments on solid-state sensitization will become possible once a structured solid solution of monomer and sensitizer can be obtained. On the synthetic side mixed dimers of predictable stereochemistry will become accessible. Other lines of work are conceivable, and some of them will be discussed below.

Having tried to place solid-state photochemical research into a somewhat personal perspective I should now like to review very briefly phase one, discuss at some length phase two, and present current work in phases three and four.

\section{THE TOPOCHEMICAL ARGUMENT}

The classes of photodimerizable compounds to which the topochemical rules apply, have been summarized in a paper submitted to the Solvay meeting on the Photo-excited Organic Molecule in 1967 and published in condensed form $^{8}$; there is no need to quote this material in detail. More recent and unpublished material will be referred to below.

The very high yield of $\mathrm{C}_{4}$-dimer (up to 90 per cent) from $\alpha, \beta$-unsaturated carbonyl compounds, and its equally high sterical purity, particularly as compared with solution reactions, strongly argue for effective lattice control over the dimerization reaction. Its all-or-none-nature, i.e. photoreactivity or light-stability, is further evidence. Finally, dependence of reactivity and of the stereostructure of the product on the structure of each of the polymorphic crystalline phases of a given monomer is proof positive for the interrelationship of crystal structure and reaction course.

The topochemical rules state that the stereochemistry of the dimer ( $\overline{1}$ or $m$ ) is determined by the contact geometry [antiparallel (i.e. related by a crystallographic centre of symmetry) or parallel (i.e. related by a translation axis)] of nearest-neighbour double bonds, provided that the centre-to-centre distance $d$ of these double bonds is of the order of $4 \AA$ (experimentally observed limits $4.2>d>3.5 \AA$ ) $\dagger$.

$\dagger$ The limit of $4.2 \AA$ is set by the absence of experimental data in the range 4.2 to $4.7 \AA$, and is not to be construed necessarily as an upper limit of dimerizability. At $4.7 \AA$ and above reaction does not take place. 


\section{G. M. J. SCHMIDT}

The structure of the cyclodimers correlates very well with the contact geometry of nearest-neighbour monomer molecules in the reactive crystal structures of trans-configurated $\mathrm{Ar}$. $\mathrm{CH}: \mathrm{CH}$. COR systems where $\mathrm{Ar}=\mathrm{C}_{6} \mathrm{H}_{5}$ and substituted phenyl, 2-furyl, 2-thienyl, pyridyl and $\mathrm{R}=\mathrm{OH}, \mathrm{OMe}, \mathrm{OAr}$, $\mathrm{NH}_{2}, \mathrm{NHR}, \mathrm{Ar}^{18-20}$ and of $\beta$-unsaturated lactones (coumarins) ${ }^{21}$, lactams (e.g. pyrimidines) ${ }^{22}$, and $p$-quinones ${ }^{23}$. The photobehaviour of fumaric acid derivatives ${ }^{24,25}$ including fumaronitrile follows the topochemical rules, as do the symmetrically and unsymmetrically substituted 1,4-butadiene derivatives trans,trans- and cis,cis-muconic acids (including derivatives of the former) ${ }^{26}$, sorbic acid and sorbamide ${ }^{27}$ (see below).

There is evidence from the solid-state chemistry of $p$-quinones that the formation of oxetanes follows the topochemical requirement of proper parallel alignment of $>\mathrm{C}=\mathrm{C}<$ and $>\mathrm{C}=\mathrm{O}$ bonds ${ }^{23}$. More recently, substituted trans-stilbenes ${ }^{28}$ and trans,trans-1,4-diphenylbuta-1,3-dienes ${ }^{29}$ have been shown to undergo topochemically controlled dimerization indicating that the carbonyl-function is not an essential feature of $\mathrm{C}_{4^{-}}$cyclodimerization in the solid state.
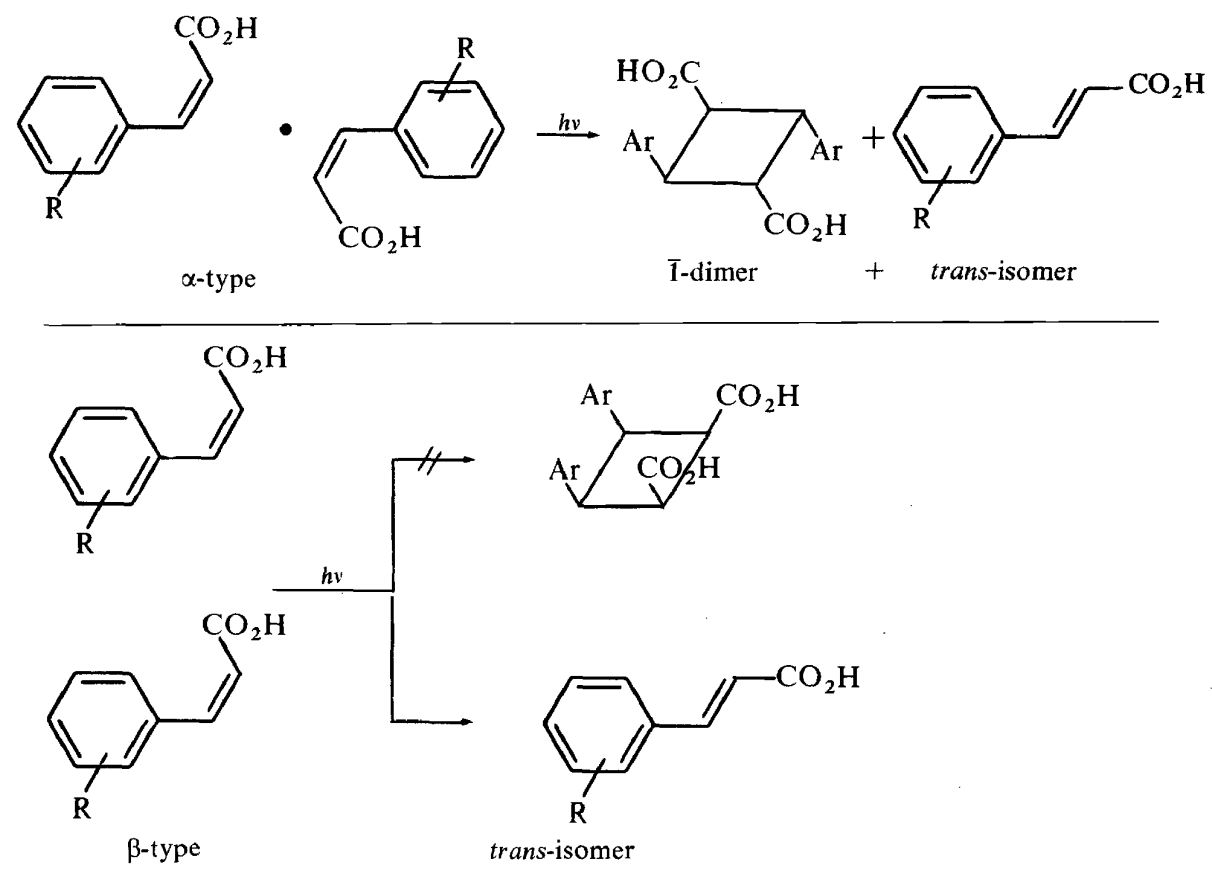

Scheme 1. The solid-state photochemistry of cis-cinnamic acids

There is limited evidence that close centrosymmetric contact of ciscinnamic acids can give the $\overline{1}$-dimer, and very much stronger evidence that close translational packing of cis-cinnamic acids does not yield the all-ciscyclobutane of symmetry $m$; in both packing types the cis-acids undergo 
isomerization to the trans-cinnamic acid ${ }^{30}$ (Scheme 1). Topochemical dimerization of cis-configurated double bonds is observed in non-aromatic systems such as cis,cis-muconic acid.

In summary, planar or near-planar monomers having appropriate packing geometry give the anticipated cyclobutane with retention of configuration of monomer geometry. Non-planar molecules (e.g. cis-cinnamic acids, $\beta$-chloro-, bromo- and methyl-trans-cinnamic acids) undergo in the main trans,cis isomerization. The photochemistry of anthracene derivatives, that is cyclization to dianthracenes, is discussed below.

We now ask how precisely the $\pi$-electron system of two double bonds must be aligned for reaction to occur. Several lines of approach to this question have been followed: In the methyl ester of $m$-bromo-cinnamic acid $^{31}$ the contact geometry of the double bonds of adjacent molecules is unusual (Figure 1): the centre-to-centre distance of $>_{\mathrm{C}=\mathrm{C}}\langle$ groups in glide-plane related molecules is short (3.93 $\AA$ ); however, the double bonds are not parallel. After irradiation over long periods during which substituted methyl cinnamates packing in the $\beta$-type have been completely dimerized, the material is essentially unchanged ${ }^{32}$.

Another demonstration of this point is provided by the photostability of the $\alpha, \omega$-diphenyl-all-trans-polyenes. As an example we show the packing arrangement of the octatetraene ${ }^{33}$ in Figure 2. The molecules, occupying centres of symmetry and being glide-plane related in space group $P b c a$, are not parallel; distances between carbon atoms such as $\mathrm{C}(7) \cdots \mathrm{C}(7)$ are short (3.7 $\AA$ ), but the separation of centres of double bonds is greater than $4.8 \AA$ throughout the crystal structure. Photoreaction does not occur; instead the material and its homologues in closely related crystal structures fluoresce very strongly. The observation ${ }^{29}$ that diphenylbutadienes in the $4 \AA$ packing arrangement yield photodimers, eliminates the possible argument that these polyenes are intrinsically incapable of dimerization in the solid state.

The specificity of molecular contact geometry required for dimerization in the rigid phase is well demonstrated by the photobehaviour of cis-cinnamic acids. We have earlier reported ${ }^{30}$ that the photoreaction of cis-cinnamic acids leads to trans-acids and the topochemical photoproducts of the latter, and concluded that this process takes place in the sequence of events in equation 1

$$
\begin{aligned}
& \{\text { cis }\} \stackrel{\text { hy }}{\rightarrow}\{\text { cis,trans }\} \stackrel{\Delta}{\rightarrow}\{\text { cis }\}+\{\text { trans }\} \\
& \text { photoproducts of the crystal forms of trans-acids }
\end{aligned}
$$

that is, the trans-isomer is formed in solid solution within the cis-lattice from which it separates in a thermally controlled recrystallization step into its own lattice. There was no evidence of cross-dimers from a molecule each of cis-and trans-cinnamic acid, although the latter was clearly located in the immediate neighbourhood of the former. To check this point two systems were investigated in quantitative detail ${ }^{34}$, see Schemes 1 and 2 overleaf. (1) is partially converted to the cis-isomer (2) which is light-stable in its own crystal structure, and partially dimerized to centrosymmetric cyclobutane (3). 


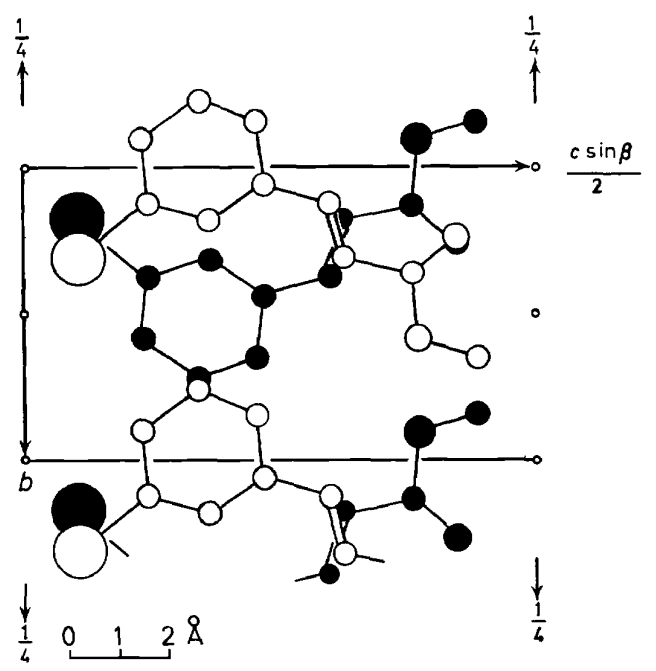

Figure 1. Methyl-m-bromocinnamate. Packing arrangement seen along [100]

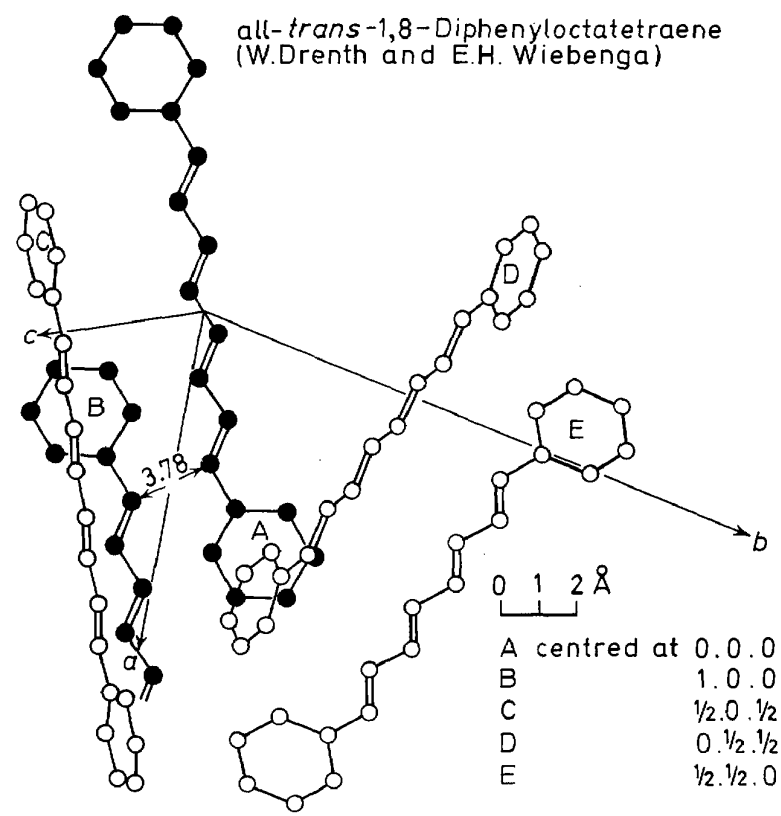

Figure 2. Packing diagram seen normal to molecular plane of molecule $\mathrm{A}$ at $(x, y, z)$ 
PHOTODIMERIZATION IN THE SOLID STATE
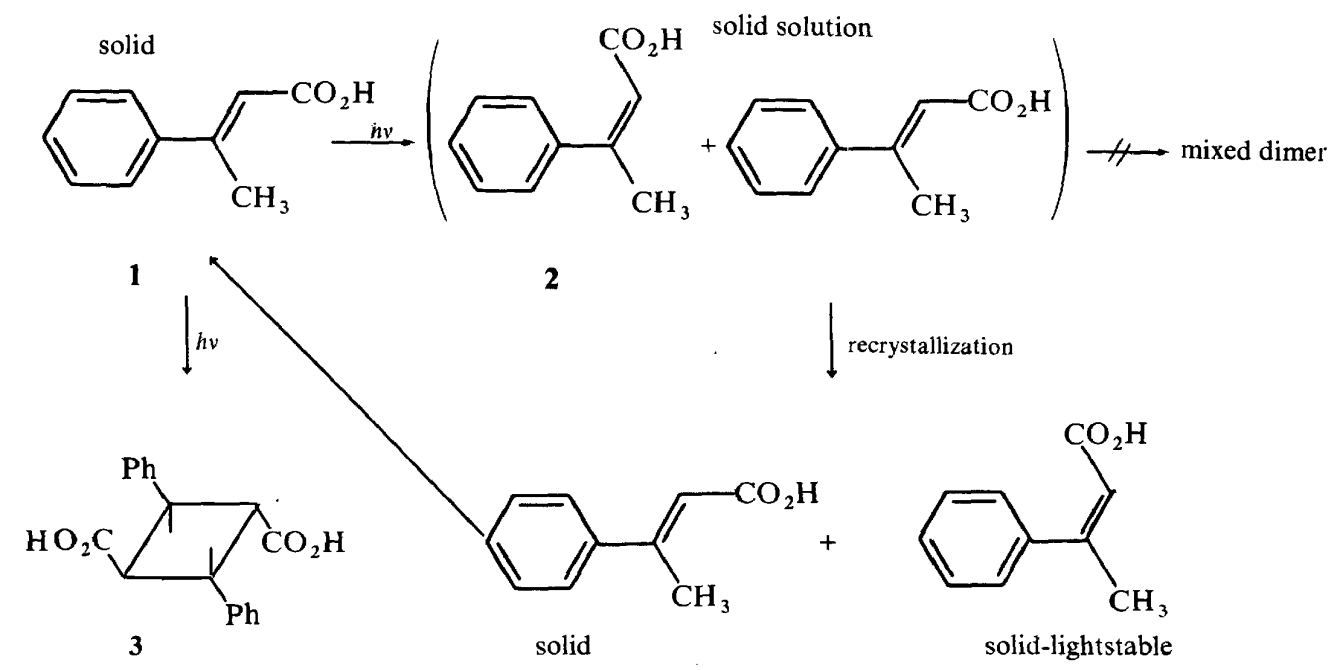

Scheme 2 . The solid-state photochemistry of $\beta$-methyl-trans-cinnamic acid

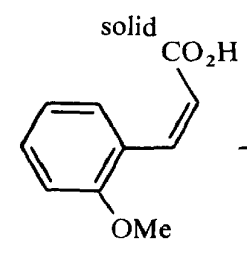

4

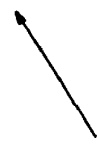

solid solution

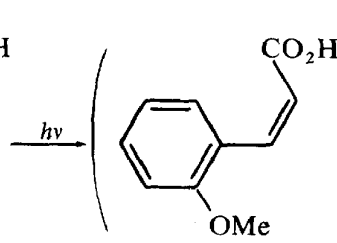

$\mathrm{OMe}$

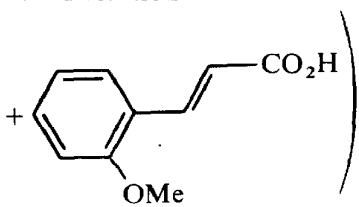

5<smiles>CC(C)(C)[GeH2][Mg][Mg]</smiles>

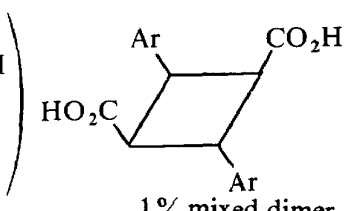

7

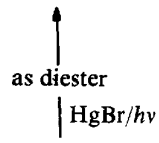<smiles>COc1ccccc1/C=C\C(=O)O</smiles>

solid

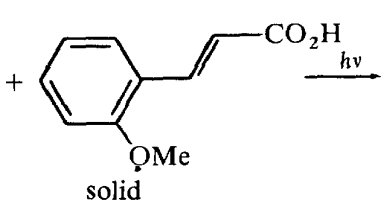

solid

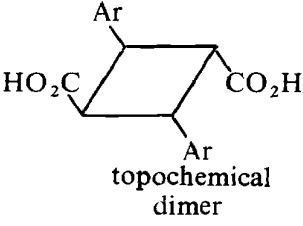

6

Scheme 3. The solid-state photochemistry of $o$-methoxy-cis-cinnamic acid 
VPC analysis of the esterified (diazomethane) reaction mixture shows the presence of the three components (1), (2) and (3) and essentially negligible amounts of another product, possibly a second dimer (Scheme 2). Similarly the cis-acid (4) is converted to the trans-isomer (5) which we know to be capable of dimerization to the centrosymmetric cyclobutane (6). Again, VPC analysis of the esterified reaction mixture shows the three components (4), (5) and (6), and a trace (less than one per cent) of a second dimer. The last was tentatively identified on the basis of retention time as (7) prepared independently from the $\alpha$-dimer (6) by epimerization with mercuric bromide and light ${ }^{35}$ (Scheme 3.)

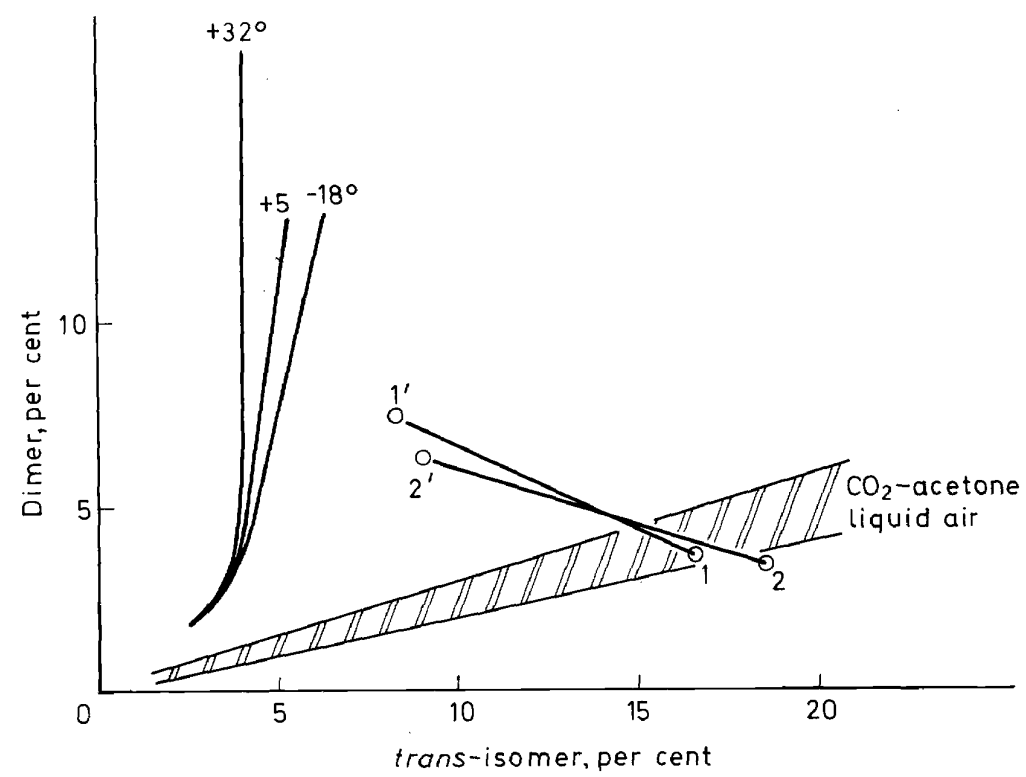

Figure 3. o-Methoxy-cis-cinnamic acid. Product distribution at various temperatures

Thus in both systems solid solutions are formed during the course of continuous irradiation, containing both cis- and trans-isomers in what must be obviously close juxtaposition. In spite of the presence within the solid matrix of the two isomeric species, cross-dimerization between trans- and cis-acids takes place to only negligible extent. This picture has been further clarified by Mr Ron's study of the system (4) at various temperatures (Figure 3). Photoreaction of the cis-acid (4) at room temperature produces mainly dimer (6) whose yield increases with exposure time while the amount of trans-isomer remains constant at about four or five per cent. At lowtemperatures (between $-80^{\circ}$ and $-180^{\circ} \mathrm{C}$ ) trans-isomer accumulates and relatively little dimer is formed. That this low-temperature effect is not due to a slow-down of the dimerization process could be established in independent experiments demonstrating negligible temperature dependence of the photoreaction of the trans-acid. Instead, it is caused by the absence of recrystallization of the 
solution of trans- in the lattice of cis-acid: samples such as represented by points 1 and 2 in Figure 3 which had been irradiated at $-80^{\circ}$ and $-180^{\circ} \mathrm{C}$ respectively, were warmed in the dark, to $+60^{\circ} \mathrm{C}$ for a period of $20 \mathrm{~h}$, then re-cooled to $-80^{\circ}$ and $-180^{\circ} \mathrm{C}$, re-irradiated for another short period, and analysed to the composition shown in points $1^{\prime}$ and $2^{\prime}$. This line of experimentation strongly suggests that the thermally activated step is the recrystallization of the solution of photoproduct in the lattice of the starting materials, whose activation energy must be of the order of magnitude of the heat of sublimation of the monomer crystal, i.e. in the neighbourhood of 20 to $30 \mathrm{kcal} / \mathrm{mole}$, characteristic of organic crystals. If this interpretation is accepted then the low-temperature accumulation of trans-monomers strongly supports the topochemical argument that dimerization is very precisely controlled by the alignment of nearest-neighbours, even in the ground state.

There is no doubt that the example quoted here of the absence of crossdimerization in a solid solution of product in monomers is an extreme case: in systems such as the pyrimidines 'errors' in dimerization arise after (varying) degrees of conversion to the topochemical product.

The phenomenon of photo-crosslinking of polyvinyl cinnamates, recently reviewed by Williams ${ }^{36}$ should be mentioned at this stage; while u.v. irradiation produces diminution of the absorbance in the region characteristic of the cinnamate group there is very little evidence that the products are cyclobutanes: Sonntag and Srinivasan ${ }^{37}$ claim to have demonstrated the presence of $\alpha$-truxillic acid among the hydrolysis products of irradiated poly(vinylcinnamates). On the other hand, the e.s.r. spectrum ${ }^{38}$ of the polymer irradiated with $240-250 \mathrm{~nm}$ at $77^{\circ} \mathrm{K}$ indicates that at least two radical species are present, one of crosslinked cinnamoyl radicals, the other belonging to radicals on the main chain; unfortunately the exciting wavelength chosen is rather short, it being known that at this wavelength diphenylcyclobutanes are split; experiments at longer wavelengths, say near $300 \mathrm{~nm}$, would be desirable. Although the literature speaks of cyclobutanes formed by the crosslinking process of cinnamate-containing polymers the evidence for intra- or inter-strand cyclodimerization is of very limited value; until more reliable data for cyclobutane become available the problem of cyclodimerization of not necessarily parallel cinnamoyl residues must be left in abeyance.

Summarizing this discussion of the topochemical rules as they apply to the photodimerization of $\alpha, \beta$-unsaturated acids we conclude that the exact parallel alignment, within a regular crystal lattice, of double bonds is an essential pre-requisite for cyclodimerization.

\section{THE LOCUS OF THE REACTION}

A meaningful discussion of the mechanism of reactions in the solid state requires the precise definition of the locus of the chemical event. On the one hand, $x$-ray structure analysis, which has provided the basis for the topochemical arguments, describes the crystalline species as an idealized timeand space-averaged three-dimensional repeat pattern: on the other hand we know that the real solid has surfaces, grain boundaries, dislocations adsorbed molecules, substitutional and other impurities (e.g. occluded 
solvent), and other defects which are not readily or not all detectable by $\mathrm{x}$-ray diffraction techniques.

Since molecules sited at surfaces or dislocations are likely to have a higher chemical potential than molecules in the bulk phase the assumption is justified that thermal reactions will take place at the discontinuities; again, those photochemical reactions in which energy is transported through the bulk phase composed of suitably overlapped $\pi$-systems, are more likely to occur at these sites than in the bulk because these irregularities can serve as traps in the exciton-propagation mechanism. It is not obvious a priori whether reaction at these particular sites is subject to the topochemical rules though, as we have seen, the topochemical approach adequately described the photochemistry of $\alpha, \beta$-unsaturated acids etc. On the other hand, evidence has been accumulating ${ }^{8,10}$ that the photobehaviour of anthracene, 9-cyanoanthracene and 9-anthraldehyde could not be reconciled with the crystal structure of the monomers, and Craig and Sarti-Fantoni ${ }^{10}$ suggested that 'reaction occurs at defects or surfaces or zones already disordered by dimerization'.

A systematic chemical and crystallographic study in our Laboratory by Drs E. Heller ${ }^{39}$ and J. C. J. Bart has shown that the substituted anthracenes fall into at least three packing types corresponding to our $\alpha, \beta, \gamma$-classification : in the $\gamma$-types [e.g. 9-methoxyanthracene ${ }^{40}$, Figure 4 ; 1-cyanoanthracene; 1-chloroanthracene] the molecular planes are not parallel and the distances between the meso-atoms of neighbouring molecules greater than $5 \AA$. As expected these compounds are lightstable in the crystalline phase though they photodimerize in solution.

In the $\alpha$-type anthracene units are packed pairwise across centres of symmetry such that the $C(9) \cdots C\left(10^{\prime}\right)$ distances are short $(3.6 \AA)^{40}$ (Figure 5). With the exception of 9-nitroanthracene monosubstituted anthracenes crystallizing in the $\alpha$-type, whether substituted at position $9(\mathrm{R}=\mathrm{Cl}, \mathrm{Br}, \mathrm{Me}$, $\mathrm{CO}_{2} \mathrm{Me}$ ) or elsewhere [1-chloroanthracene (second modification)] produce the topochemically expected 1-dimer in high yield.

The anthracene derivatives which crystallize in the $\beta$-type fall into three classes (Scheme 4): first, 1,5-dichloroanthracene and the 2,4-dichlorophenyl ester of 1-anthroic acid which dimerize to the (topochemical) head-to-head dimers; secondly, a lightstable group $\left[\mathrm{R}=\mathrm{Br}, \mathrm{CO}_{2} \mathrm{Me}\right.$ (both second modifications); $\left.\mathrm{CO}_{2} \mathrm{H}\right]$ and, third, a group yielding the $\overline{1}$-dimer $[\mathrm{R}=\mathrm{Cl}$ (second modification); CHO; CN (Figure 6)]. Thus, of these three groups only the one substituted elsewhere than at the meso-position gives the headto-head $m$-dimer expected on geometrical grounds, whilst the 9-substituted derivatives either do not react or give the non-topochemical head-to-tail dimer.

Now it is known that all 9-substituted monomers, even on photodimerization in solution, yield only the head-to-tail dimers and do not produce the head-to-head dimers; the conclusion has been drawn that $9,9^{\prime}$-substituted head-to-head dimers cannot be formed, at least under photochemical conditions. If we accept this conclusion then the behaviour of the lightstable anthracenes in the $\beta$-type is in effect topochemically normal since the headto-head product is presumably unstable. The formation of the centrosymmetric dimers from parallel monomer molecules in the $\beta$-packing mode 


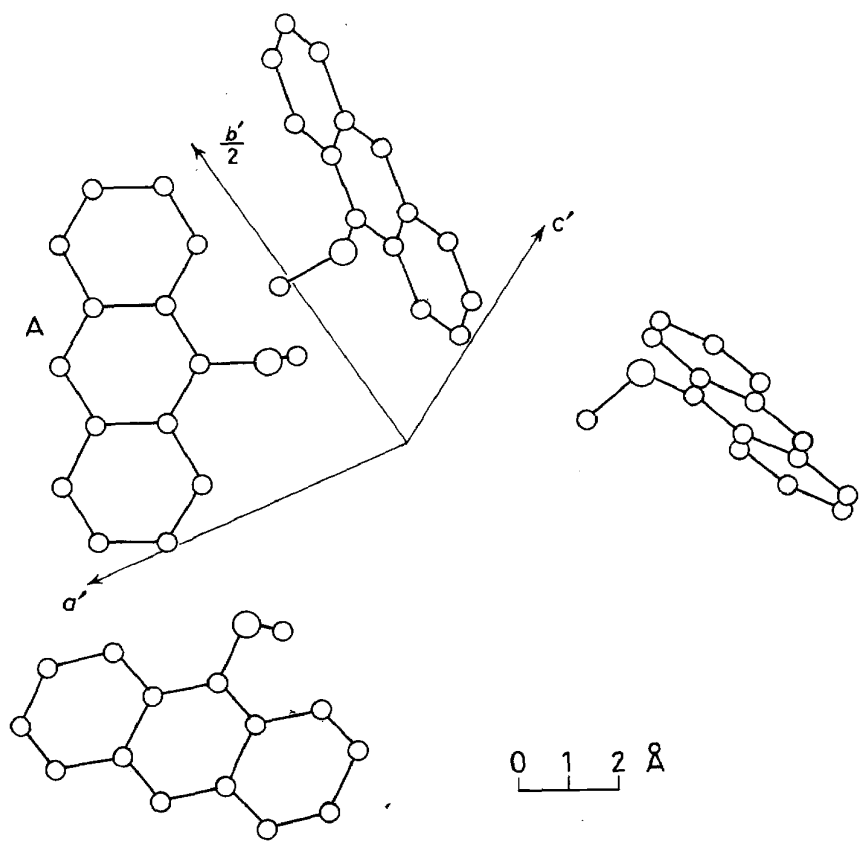

Figure 4.9-Methoxyanthracene. Packing diagram seen normal to molecular plane of molecule A at $(x, y, z)$

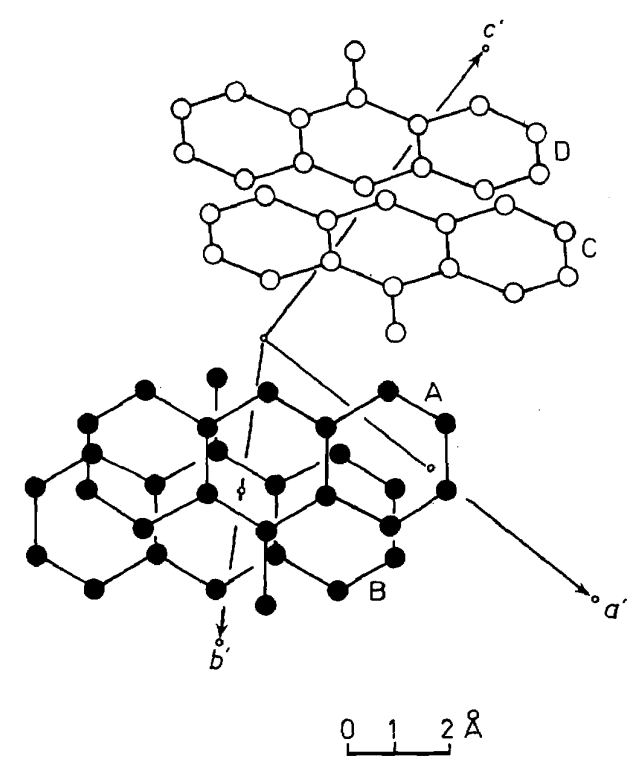

Figure 5. 9-Methylanthracene. Packing diagram seen normal to molecular plane of molecule A at $(x, y, z)$ 
<smiles>c1ccc2cc3ccccc3cc2c1</smiles>

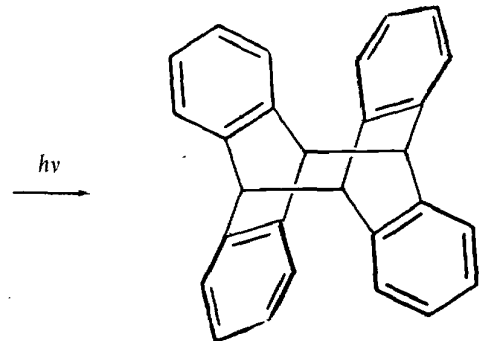

$\beta$-type

1-(2,4-dichlorophenoxycarbonyl) $h v$ 1,5-dichloro

$\stackrel{h v}{\rightarrow}$ Head-to-head dimer

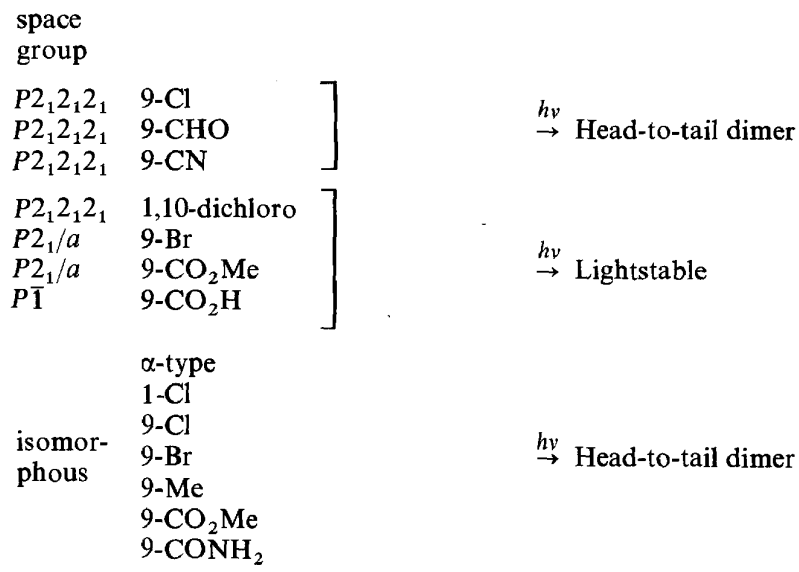

Scheme 4. Photodimerization of anthracenes

must be due to an abnormality of their crystal structures, such as the presence of dislocations which permit dimerization; such dislocations are, by implication, absent in the lightstable subclass. These photoactive dislocations have indeed been demonstrated in anthracene crystals, which were held responsible by Thomas and Williams ${ }^{11}$ for the 'topochemically forbidden' dimerization of solid anthracene, as well as in 9-cyanoanthracene ${ }^{41}$.

In summary: light stability in the solid state of monomers which can photodimerize in solution; the existence of two crystal forms of the same monomer which are lightstable and dimerizable respectively; the formation of the topochemically expected dimers from centrosymmetrically closepacked anthracenes and from translationally close-packed anthracenes substituted elsewhere than in the 9-position, argue for topochemically controlled reactions between nearest neighbours. The formation of 1 -dimers from some but not all 9-substituted monomers packing in the $\beta$-type must mean that the particular dislocations present in the photo-active forms bring about contact of monomer molecules of the correct geometry for photodimerization to be possible; equally, whatever the disclocations present 


\section{PHOTODIMERIZATION IN THE SOLID STATE}

in the photostable $\beta$-type, they are apparently not of suitable structure to cause the close antiparallel packing of monomer units which would permit formation of the head-to-tail dimer. It follows that the molecular environment at a particular dislocation may, but need not, be favourable to dimerization and, conversely, that the formation of 'topochemically forbidden' dimers is an indication of a dislocation type which brings monomers into correct geometrical juxtaposition for dimerization.

\section{9-Cyanoanthracene (A.Rabaud and J.Clastre)}

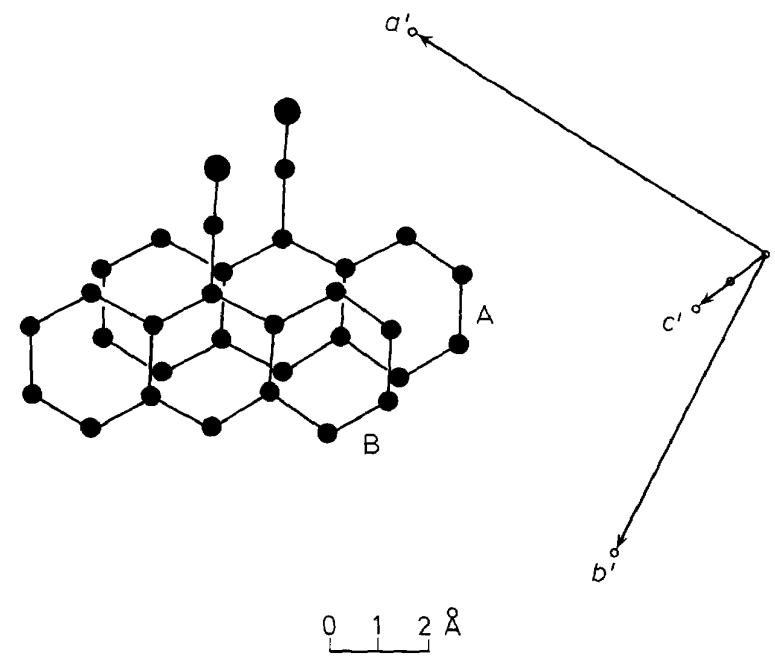

Figure 6. Packing diagram seen normal to molecular plane of molecule A at $(x, y, z)$ : Molecule B at $(x, y, 1+z)$

An alternative explanation according to which non-topochemical dimerization occurs at sites of high molecular mobility not requiring correct molecular alignment prior to reaction is ruled out by our results on the photo-chemical behaviour of 1,5-dichloroanthracene ( $\beta$-type) and 1-chloroanthracene ( $\alpha$ - and $\gamma$-types): irradiation of solutions of these two monomers yielded the theoretical number of dimers (two and four, respectively); the light-active solids gave each the one topochemical dimer. Thus, while these monomer molecules can take up, in the dissolved phase, all mutual orientations, to produce all possible dimers, they are not free to move in their crystal structures: solid-state dimers are only formed from correctly pre-aligned and sufficiently close nearest neighbours.

Therefore, even in systems at first sight not obeying the topochemical rules cyclodimerization in fact takes place between correctly aligned monomer units at sufficiently short distances, such alignment being provided, if not by the bulk of the crystal lattice, then by dislocations of appropriate geometry. 


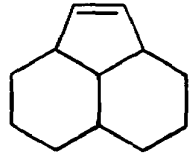

8

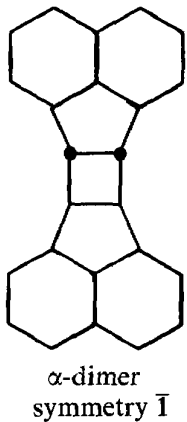

9

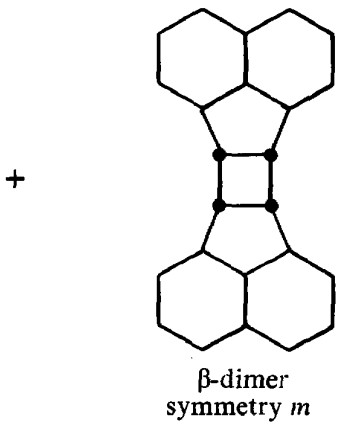

10

Scheme 5. Photoproducts of acenaphthylene

When we undertook a detailed study of the photochemistry of solid acenaphthylene (8) (Scheme 5) much information on the reaction to the two dimers (9) and (10) was already available. A recent study ${ }^{42}$ had claimed the formation of the 1-dimer (9) with essentially zero 'energy of activation' and of the $m$-dimer (10) with $\Delta E^{*} \sim 40 \mathrm{kcal} / \mathrm{mole}$. The solid-state radiation chemistry of acenaphthylene had been investigated by Chapiro and Lozach ${ }^{43}$ who observed similar kinetics of dimerization and pointed out that acenaphthylene was the first hydrocarbon to undergo radiochemicallyinduced cyclodimerization. The solution photochemistry had also been studied in detail by several groups ${ }^{44}$.

The mechanism of solution dimerization is now pictured as proceeding to the $c i s$-isomer from a $\pi$-complex probably via the singlet excited state; the trans-isomer is believed to derive from the triplet excited state sufficiently long-lived to permit a normal bimolecular reaction with a ground-state monomer molecule. The conclusion that the $m$-dimer was formed in a solidstate reaction requiring an activation energy as high as $40 \mathrm{kcal} / \mathrm{mole}$ seemed to us inherently improbable; indeed, the very complexity of the photochemical system suggested novel features worthy of further investigation. Our work can be summarized as follows: photoreaction to the $\overline{1}$-dimer takes place not in the bulk of the crystalline material but only at disclocations; this observation, i.e. the decoration of the dislocation lines by dimer, was the first example of such an effect in organic crystals, for the recognition of which we are indebted to Professor Thomas ${ }^{12}$. Irradiation of acenaphthylene films between two quartz plates (rather than with crystals contained in vessels with free volume) has shown that formation of the $m$-dimer is inhibited, even at temperatures greater than $50^{\circ}$, throughout the film except at crystal discontinuities such as cracks, holes, etc. The value of the heat of sublimation $\left(\Delta H_{\text {subl. }}=15.4 \mathrm{kcal} / \mathrm{mole}\right.$, determined here from vapour pressure measurements) is low, compared with, say, acenaphthene $(19.7 \mathrm{kcal} / \mathrm{mole})$ and naph thalene $(17.4 \mathrm{kcal} / \mathrm{mole})$, and suggests that the gas phase in vessels where free volume is appreciable, should be considered as a possible locus of 


\section{PHOTODIMERIZATION IN THE SOLID STATE}

reaction. A simple calculation which assumes that $m$-dimer arises from absorption of a photon by a pre-associated pair in the vapour phase leads to a value of a minimum of the 'activation energy' of $2 \Delta H_{\text {subl. }}=31 \mathrm{kcal} / \mathrm{mole}$, a value which may account for the observed value of $40 \mathrm{kcal} / \mathrm{mole}$ for 'solid state' reaction.

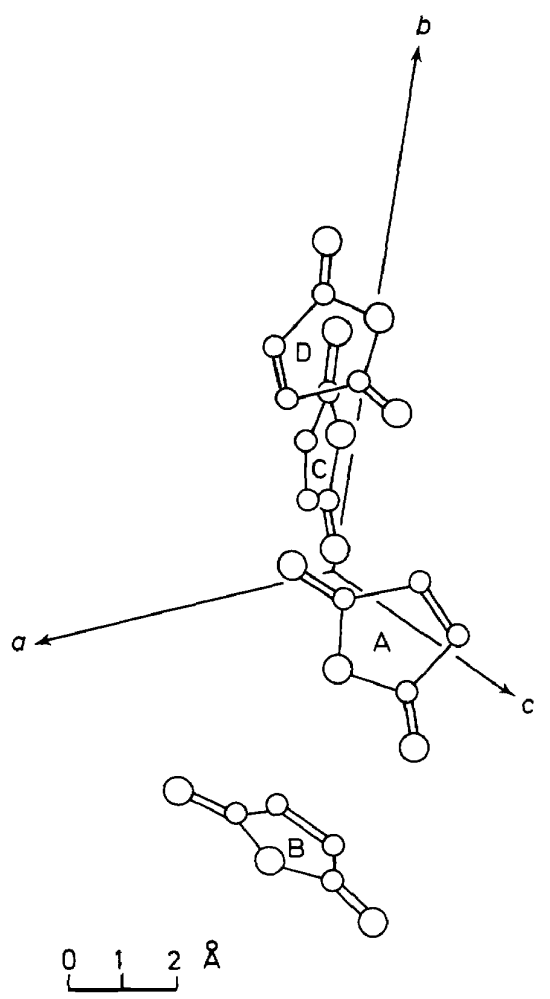

Figure 7. Packing diagram seen normal to molecular plane of molecule $\mathrm{A}$ at $(x, y, z)$. Maleic anhydride (R. E. Marsh, E. Ubell and H. E. Wilcox)<smiles>O=C1C=CC(=O)O1</smiles>

$\stackrel{h v}{\longrightarrow}$

11<smiles>O=C1OC(=O)C2C1C1C(=O)OC(=O)C21</smiles>

12

Maleic anhydride (11) has been reported ${ }^{45}$ to photodimerize to (12), in a yield of less than nine per cent after exposure for $240 \mathrm{~h}$. The crystal structure of the monomer ${ }^{46}$ shown in Figure 7 has neither parallel nor short contacts between $-\mathrm{CH}=\mathrm{CH}-$ groups and appears unsuited to photodimerization. Experiments in this Laboratory ${ }^{34}$ indicate essentially complete inhibition of dimer formation at $5^{\circ}$. In view of the high vapour pressure of maleic anhydride at room temperature we suggest that the reaction takes place in the vapour phase and not in the crystal. 


\section{CRYSTAL ENGINEERING}

Systematic work on the forces controlling molecular packing arrangement is leading to the evolution of a general theory of crystal structures. A number of attempts ${ }^{13,14}$ are being made to derive unit-cell dimensions of compounds from potential-energy curves accounting for molecular interaction, particularly of small and medium-sized aromatic systems. A more qualitative approach is being followed in our Laboratory by Dr Leiserowitz ${ }^{15}$ who has considered the packing types of primary amides (including $\alpha, \beta$-unsaturated derivatives) in terms of the geometry of the hydrogen-bonded networks generated by the $-\mathrm{C}_{\mathrm{NH}_{2}}$ groups. From this study resulted the observation that the probability of $\alpha, \beta$-unsaturated amides crystallizing in the (photodimerizable) $\alpha$-type was very high, certainly higher than for the corresponding acids, and further that their packing arrangements, except for minor differences in molecular conformation, were sufficiently similar to suggest binary miscibility studies of primary amides. These are discussed below.

A second approach to controlled packing geometry has been found in the introduction of a dichlorophenyl group into unsaturated systems ${ }^{16}$, which brings about crystallization in a unit cell having a shortest axis of $\sim 4 \AA$. By this method a large number of compounds of the type $\operatorname{Ar}(\mathrm{CH}: \mathrm{CH})_{m}^{-} \mathrm{X}$, where $\mathrm{Ar}=2,4-, 3,4-$, and 2,6-dichlorophenyl; $(m=0,1) ; \mathrm{X}=\mathrm{CHO}, \mathrm{CO}_{2} \mathrm{H}$, $\mathrm{CO}_{2} \mathrm{Me}, \mathrm{CN}, \mathrm{NO}_{2}, \mathrm{Ph}, \mathrm{CO}(\mathrm{CH}: \mathrm{CH})_{n} \mathrm{Ph}(n=0,1)$ have been obtained in the $\beta$-packing type, and their photoproducts characterized as $m$-dimers appropriate to this packing type.

As an alternative technique of forcing, the $4 \AA$ structure type $\alpha, \beta$-unsaturated ketones etc. can be co-crystallized with mercuric chloride into molecular complexes. The crystal structure of the complex is evidently controlled by the packing of mercuric chloride which itself crystallizes in a cell of dimensions $a=5.96, b=12.74, c=4.33 \AA^{49}$. Thus, coumarin ${ }^{47}$, cinnamaldehyde, benzalacetophenone ${ }^{48}$ and others give crystalline $1: 1$ complexes having $4 \AA$ axes. The topochemically expected formation of the cis,syn-dimer from [coumarin. $\mathrm{HgCl}_{2}$ ] has been described ${ }^{30}$; this totally stereospecific reaction is the easiest route to this isomer.

\section{TOWARDS A SYSTEMATIC SOLID-STATE PHOTOCHEMISTRY}

In this last section we report recent results on cyclodimerization in the solid state, some of which have become possible through the application of the packing rules sketched in the previous section, and discuss some possible future lines of research.

\section{(A) The photochemistry of 1,3-butadienes}

A survey of the crystallography of trans,trans-muconic acid (13) and its derivatives, of cis,cis-muconic acid (16) ${ }^{26}$, of crotonic (17) and sorbic acids (18) 


\section{PHOTODIMERIZATION IN THE SOLID STATE}

and derivatives ${ }^{27}$ has shown that many compounds in this series crystallize in the $\beta$-type ( $4 \AA$ axis); the structure analyses carried out here and elsewhere have shown all these molecules to crystallize in the extended planar s-transconformation in packing arrangements which should be lightactive. The photochemistry of these compounds is summarized in Schemes 6 and 7. trans,trans-Sorbamide (19) does not crystallize in the $\beta$-type, the molecules being close-packed pairwise across centres of symmetry ${ }^{50}$ : its photochemistry is summarized in Scheme 7.

13
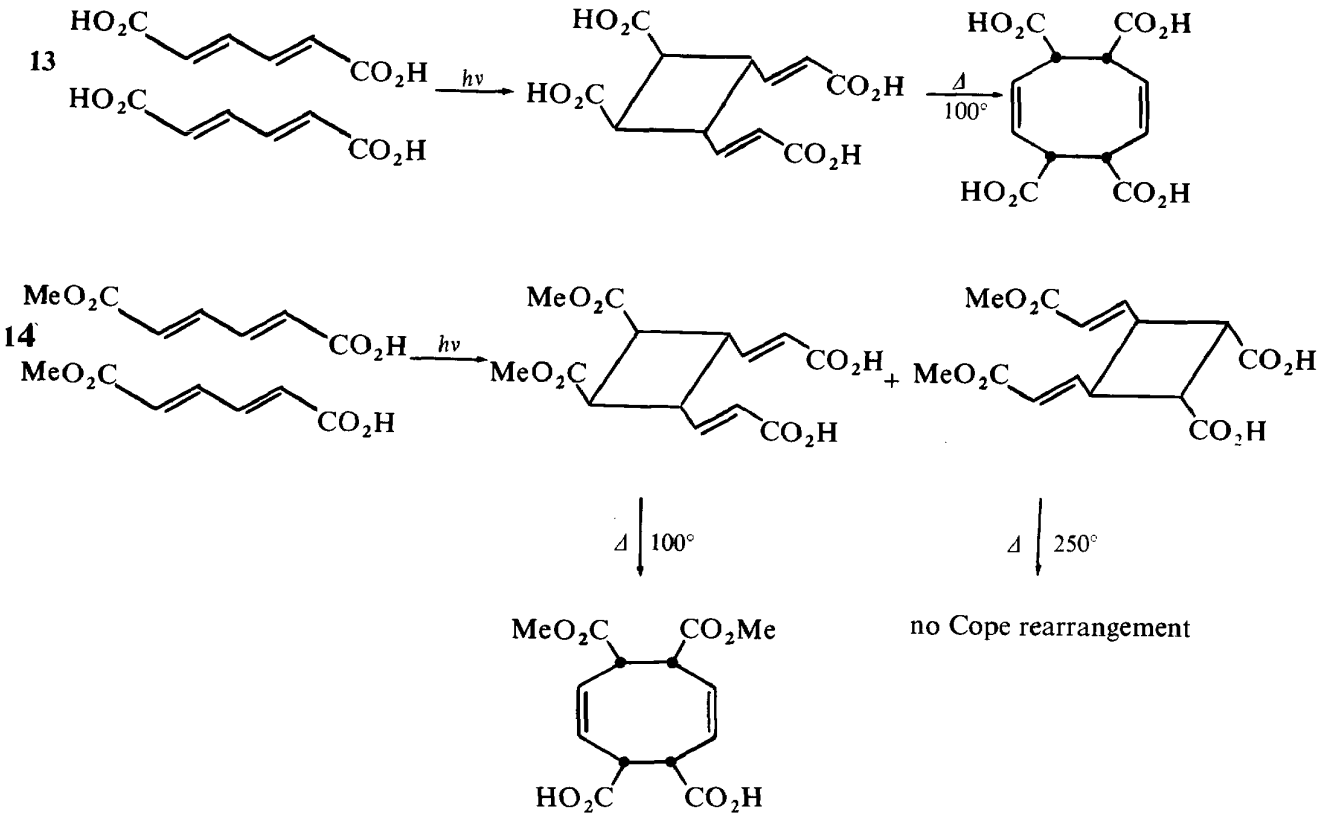

no Cope rearrangement<smiles>N#C/C=C\C=C/C=C\C#N</smiles>

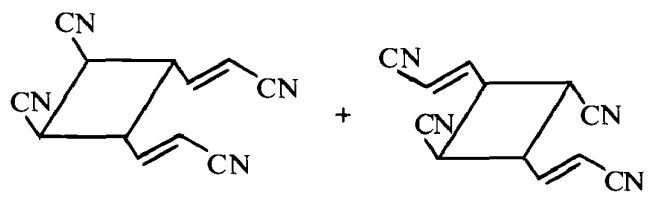

20

21

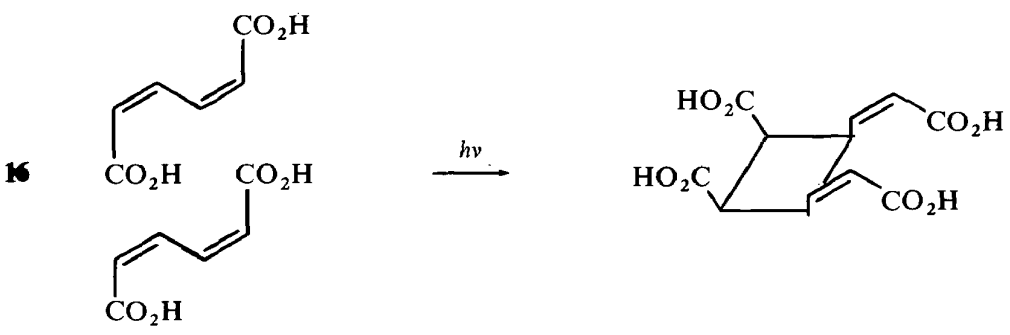

Scheme 6. Solid-state photoproducts of muconic acid and some derivatives. 
G. M. J. SCHMIDT
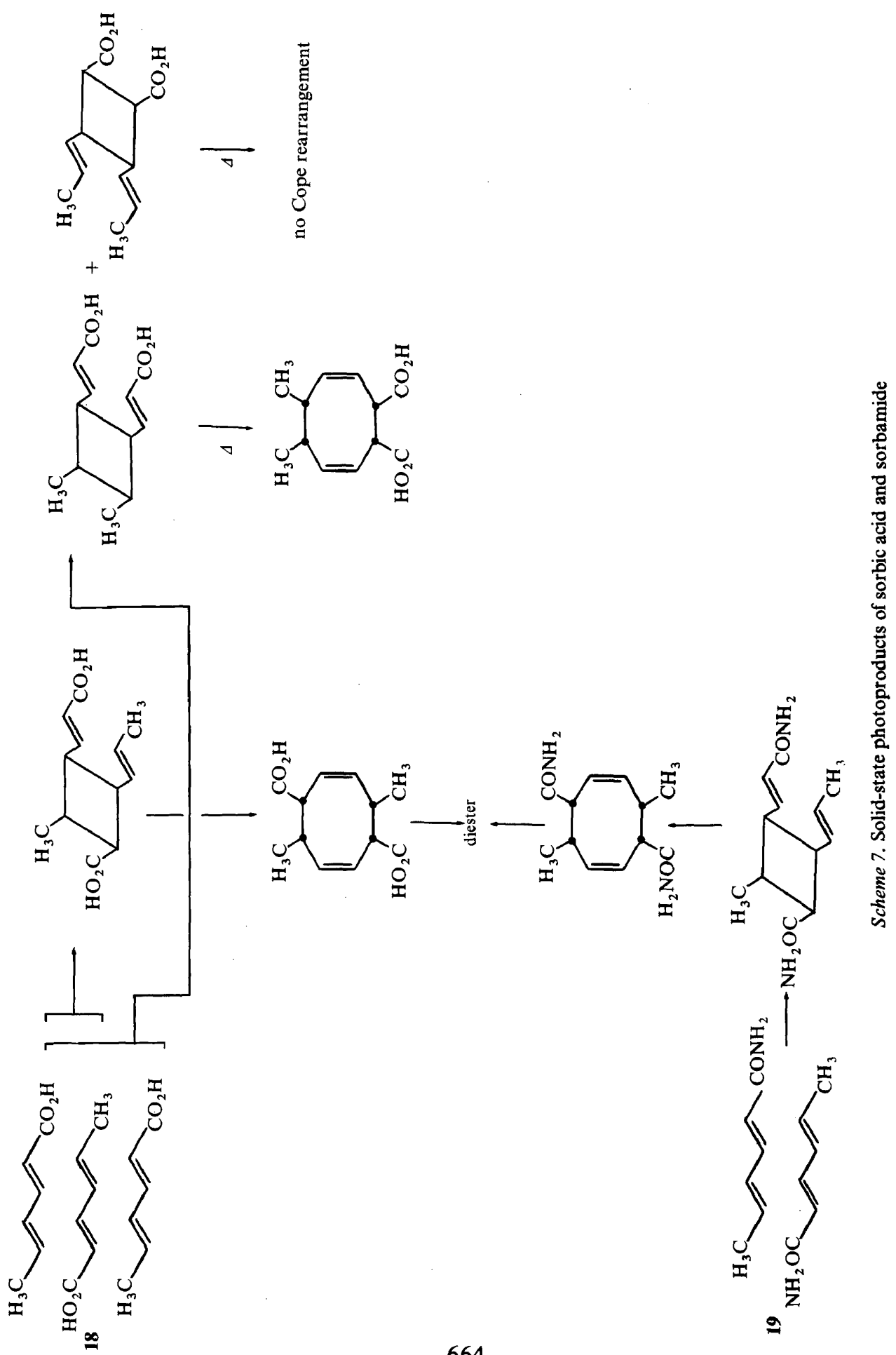
The following conclusions are of interest:

(1) The yields of 1,2-divinylcyclobutanes of the configuration required by the stereochemistry of the starting material and its packing geometry are high.

(2) Cyclobutanes having the non-topochemical configuration, if formed at all, constitute a negligible fraction of the photoproducts. In particular, dimers from the $\beta$-packing types not having symmetry $m$ and thereby suggesting rotation around the 1,2-bond after formation of the $1,1^{\prime}$-bond and prior to ring closure at bond $2,2^{\prime}$ are present, if at all, in negligible quantities.

(3) There is no evidence that trans,trans-cyclo-octadienes are formed or any of its rearrangement products ; conceivably, the small amount of (amorphous) oligomeric material which accompanies the crystalline photoproducts derives from trans,trans-cyclo-octadienes. However, these oligomers can also be rationalized as being formed via reactions not passing through the trans, trans$\mathrm{C}_{8}$-species.

(4) Some of the cyclobutanes undergo rearrangement to cis,cis-1,5-cyclooctadienes in the solid state. The Cope products have been shown to be formed in secondary thermal dark reactions.

(5) Light stability of dimethyl trans,trans-muconate follows from the packing geometry ${ }^{51}$ of the diester; a variety of photoproducts has been isolated from the (sensitized) solution reaction ${ }^{52}$.

(6) Irradiation in the long wavelength end of the absorption $(300<\lambda<350$ $\mathrm{nm}$ ) is very effective in bringing about reaction. By extrapolation from work on ethyl acrylate and diethylfumarate in which the $\pi^{*} \leftarrow n$ transition has been identified ${ }^{53}$ in the tail-end of the absorption spectrum we may perhaps assume a similar transition in the higher homologue of fumaric acid.

(7) The example of trans,trans-muconodinitrile (15) is interesting from the topochemical and mechanistic points of view : the two products (20) and (21) are formed in yields which we could not estimate accurately so far, but which are comparable. It will be noted that the monomers are geometrically related in such a way that the distances between centres of (crystallographically) non-equivalent and equivalent double bonds are 3.64 and $3.96 \AA$ respectively ${ }^{54}$. Reaction across the former leads to the centrosymmetric, and across the latter distance to the $m$-cyclobutane. The question whether both dimers are formed from the same state of the excited monomer is interesting but unanswered.

(8) Cyclobutanes are formed not only by $1,1^{\prime}-2,2^{\prime}$ but also by $1,2^{\prime}-1^{\prime}, 2$ interaction, as from muconodinitrile to (21), from trans,trans-styrylacrylamide (22) to (23), and from dimethyl hexatrienoate (24) to $(25)^{55}$ (Scheme 8). The latter pathway distinguishes the solid-state reaction from sensitized solution reactions: Hammond indicates ${ }^{56}$ that direct irradiation of liquid butadienes gives this type of dimer, but full information on this point is not available.

In summary, the photochemistry of the planar (or near-planar) cis,cis- and trans,trans-butadienes substituted in positions 1 and 4 such that at least one substituent is an electron-withdrawing group $\left(\mathrm{CO}_{2} \mathrm{H}, \mathrm{CO}_{2} \mathrm{Me}, \mathrm{CN}\right)$ leads to 1,2-divinyl substituted cyclobutanes having the topochemically expected configuration. The reaction corresponds to $[2+2]$ addition; $[4+4]$ addition to trans,trans-cyclo-octadienes is a negligible pathway of the reaction. 
<smiles></smiles>

(15)<smiles>NC(=O)/C=C/C=C/c1ccccc1</smiles>

(22)
(20)

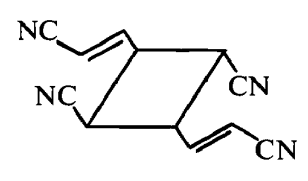

(21)

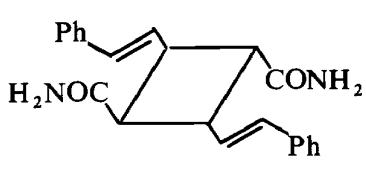

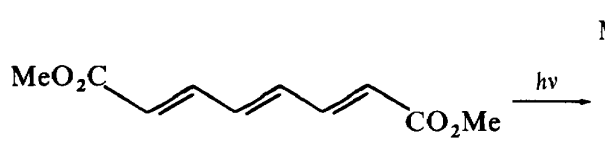

(24)
(23)

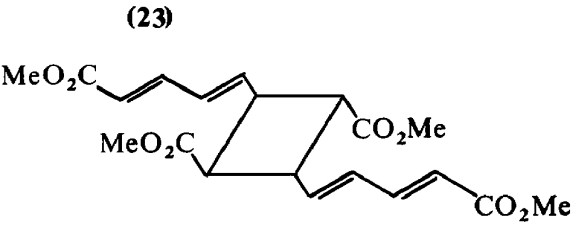

(25)

Scheme 8. 1,2'-1',2-cyclodimerization

\section{(B) Eight-centre dimerizations}

No evidence has been found for 8-centre reaction of 1,3-butadienes in the solid state to the bicyclo-octane system rather than to the observed divinylsubstituted cyclobutanes. On the other hand, the cyclization of the crossconjugated dienone (26) has been reported ${ }^{57}$, the product being claimed to be (27) on the basis of its chemical behaviour ${ }^{57},{ }^{58}$. The reaction is likely to be topochemically controlled: (26) does not give the dimer in solution, and the solid diethyl ester (28) gives polymeric material rather than dimer; the dimerization of the free dicarbocyclic acid (29) to the corresponding tetraacid has been described ${ }^{59}$. The cell dimensions of the dimethyl ester (26) were measured here: $a=15.45, b=7.92, c=3.96 \AA, \beta=102.3^{\circ} ; d_{x}=1.38 \mathrm{~g} / \mathrm{cm}^{3}$; $Z=2$. Space group: A2. Molecular symmetry: 2 . The monomer must have one or other of the two symmetric conformations $(26 \mathbf{a}, 26 \mathbf{b})$ of which the former is more probable in view of the cell dimensions. The parallel alignment of such monomers along the short $c$ axis ( $\beta$-type) suggests the configuration of the dimer to be (27); this structure differs from that proposed by Corse et al. ${ }^{60}$ which, for other reasons such as trans-fusion of the two rings at the cyclobutane, seems less plausible ${ }^{61,62}$.

The direct formation of the tricyclo[6,2,0,03, $]$ decane system in a solidstate reaction was of sufficient interest to suggest the scan for further examples ; the generalization that dichloro-substituted phenyl derivatives tend to crystallize in $4 \AA$ cells, pointed to the bis-(dichlorobenzylidene) acetones as likely to come in the $\beta$-type, and indeed several such derivatives have the desired crystal structures. Dr B. Green has investigated the derivative (30) in some detail and obtained a saturated photodimer to which we ascribe the 
PHOTODIMERIZATION IN THE SOLID STATE
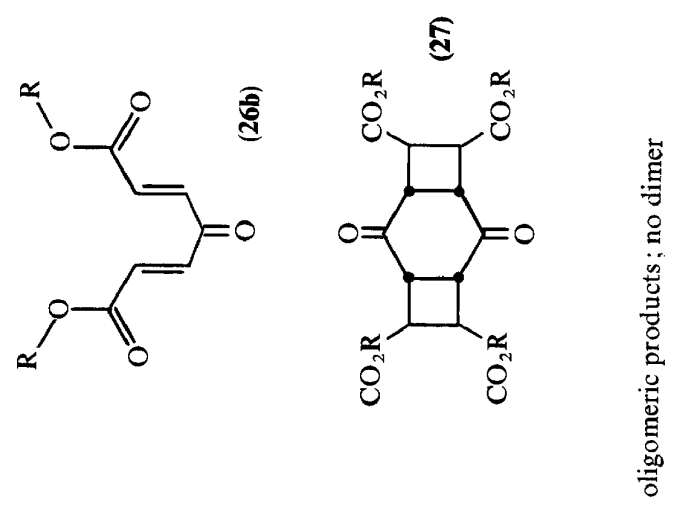

$\geq \mid$

$\frac{a}{\tilde{\Sigma}}$<smiles>[Y]COC(=O)/C=C/C(=O)/C=C/C(=O)O[Y]</smiles>

ฮีํํ बิำ

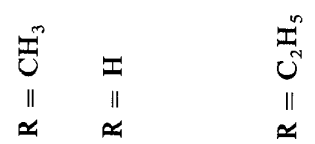


G. M. J. SCHMIDT
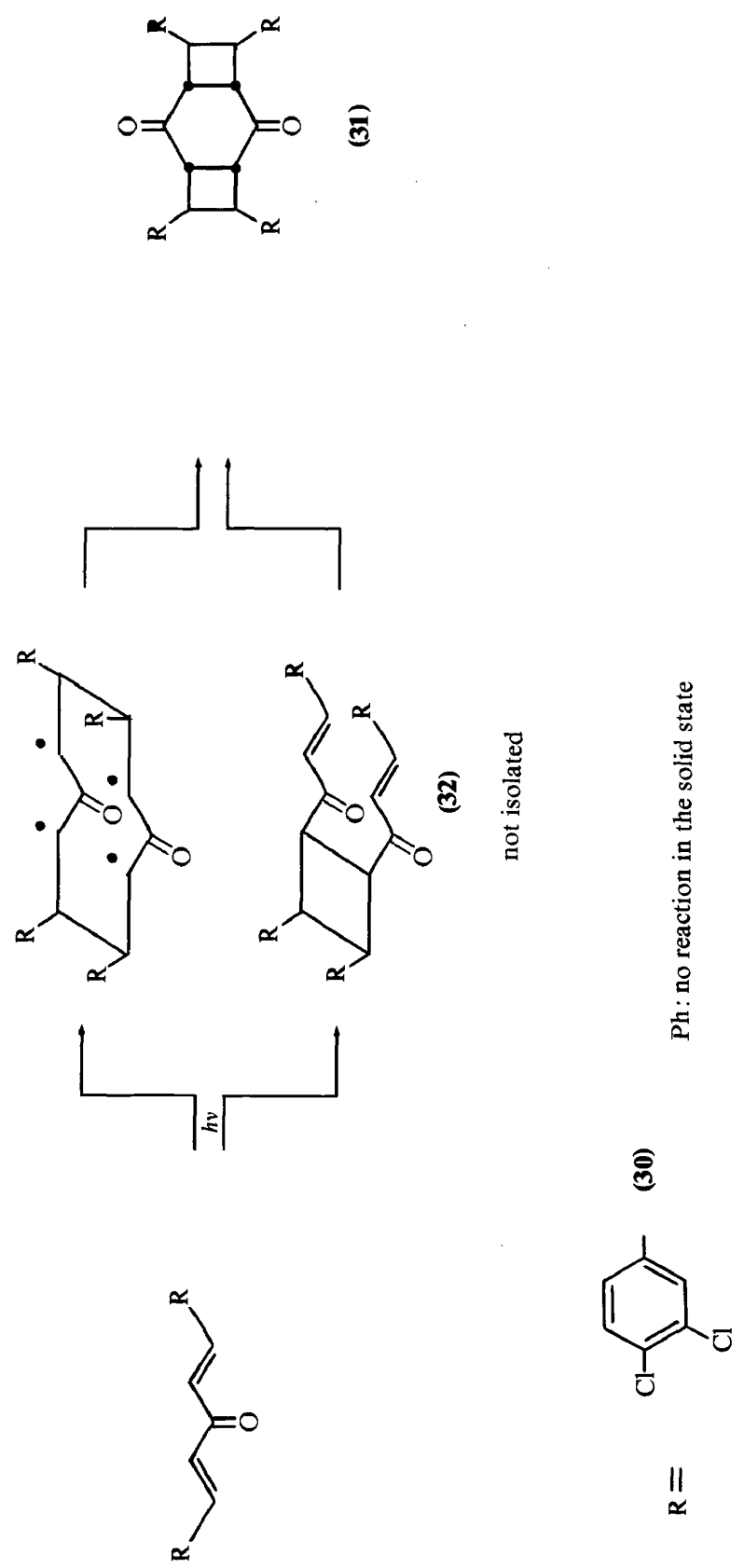
structure (31) on the basis of n.m.r., mass-spectrometric, and u.v. spectral data $^{61}$. Irradiation of the monomer with light of various short-wavelength cut-offs gave either the doubly ring-closed tricyclic system or no product at all. Light of $>470 \mathrm{~nm}$ was inactive; $\lambda>445 \mathrm{~nm}$ gave the fully saturated product but no trace of the cinnamoyl derivative (32). There can be little doubt that the reaction is monophotonic, that is, (32) in its ground state is not an intermediate in the path to the tricyclic compound (Scheme 9).

Eight-centre photopolymerization in the solid state has been noted by Japanese workers ${ }^{63-65}$ : they polymerized crystalline $p$-phenylene diacrylic acid (33), its methyl, ethyl and phenyl esters, and amide, as well as 2,5distyrylpyrazine (34) and its analogue (35) though they could not polymerize (36) or (37) under comparable conditions. The two dimerizable monomers (34) and (35) are isomorphous according to powder photographs and different from (36) and (37). The polymers from these dienes were highly crystalline; the degree of crystallinity of the diacrylic acid derivatives decreased with increasing temperature. Irradiation of the diethylester (33) in the melt failed to yield polymer. The spectroscopic (u.v., i.r., n.m.r.) data indicate the presence of cyclobutane rings in the polymers. These results suggest that the polymerization reaction is topochemically controlled; full crystallographic data on these compounds would be interesting for a description of the type of motion that these molecules undergo during the process of polymerization (Scheme 10).

\section{(C) The photochemistry of solid solutions}

The analysis of the packing arrangement of primary amides ${ }^{15}$ suggested miscibility in the solid state of $\alpha, \beta$-unsaturated amides; indeed, irradiation of several pairs of substituted cinnamides co-crystallized from the melt produced a number of unsymmetrical $\alpha$-truxillamides (heterodimers) in excellent yield alongside the two homodimers. These chemical results can be interpreted in the reverse direction; configuration of the dimers serves as a chemical probe for the orientation of monomer units in the substitutional solid solution whose detailed structure could not so far be investigated by other methods. From solid solutions of mixed monomers crystallizing in the $\alpha$-type only the symmetrical and unsymmetrical $\alpha$-truxillamides were isolated; other dimers formed were present in less than five per cent yields. Similar experiments on mixed crystals from substituted cinnamic acids crystallizing in the $\alpha$-and/or $\beta$-arrangements give useful information on the structure of substitutional solid solutions in these packing types ${ }^{66}$.

The photochemistry of solid solutions has been extended in directions of both theoretical and synthetic interest. Thus, crotonamide (12) and crotonic acid, which pack in potentially reactive crystal structures (short antiparallel and parallel contacts respectively), do not dimerize; on the other hand, the former could be incorporated into the lattice of cinnamide and of thienylacrylamide; these solid solutions yielded the mixed dimers. The precise stereochemistry of the former heterodimer is still uncertain; we tentatively propose structure (38) on topochemical grounds. A similar experiment has been carried out on the mixed system $(39,40)$ : both compounds crystallize in a $4 \AA$ cell and yield $m$-dimers, (39) being much more reactive than (40). The mixed crystal gives both (41) and the heterodimer (42) (Scheme 11). 
33<smiles>[R]O/C=C/c1ccc(/C=C/C(=O)O)cc1</smiles>

34<smiles>C(=C/c1cnc(/C=C/c2ccccc2)nc1)\c1ccccc1</smiles>
$\stackrel{h y}{\longrightarrow}$ crystalline polymer

35<smiles>C(=C/c1ccccn1)\c1ccc(/C=C/c2ccccn2)cc1</smiles>

36

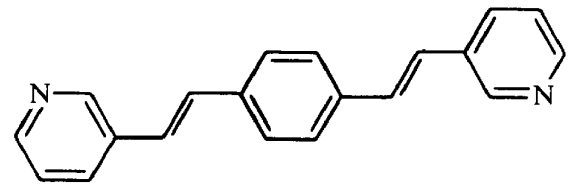

do not polymerize

37

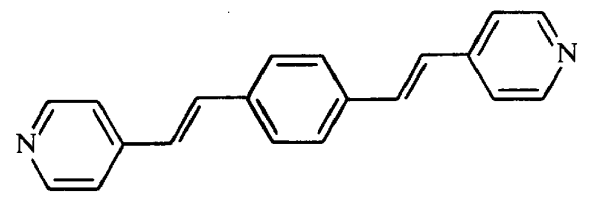

Hasegawa et al.

Scheme 10. Topochemical effects in eight-centre polymerization

Photoreactions of mixed crystals, consisting of compounds crystallizing in $4 \AA$ cells, from stilbenes-benzalanilines, stilbenes-tolanes and a variety of other pairs are under active investigation ${ }^{29}$. We return below to the significance of the mixed-crystal experiments to considerations of energy transfer.

\section{(D) Spectroscopic states and quantum yields}

Much of our work on cyclodimerization having been concerned with $\alpha, \beta$-unsaturated ketones, acids, etc. I shall confine myself to a discussion of these systems. There is no evidence for the dimerization of cinnamic acid in fluid solution; the only recorded reaction is the establishment of the photostationary equilibrium between the cis- and trans-isomers. Reaction in the presence of photosensitizers via the triplet state of the trans-acid reported to be in the neighbourhood of $50 \mathrm{kcal} / \mathrm{mole}^{67}$ has not yet been studied. 
PHOTODIMERIZATION IN THE SOLID STATE
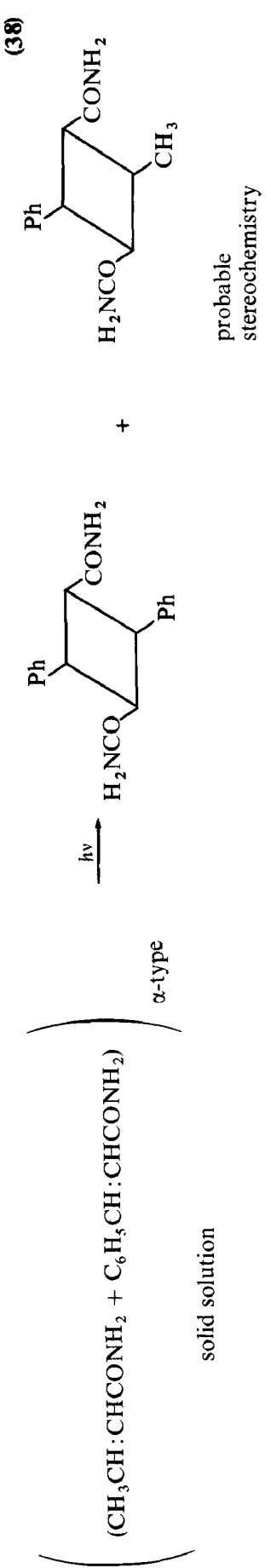

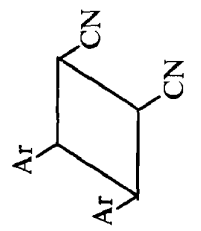

ฐิ

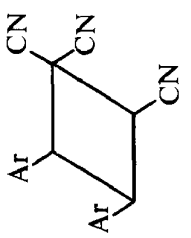

主
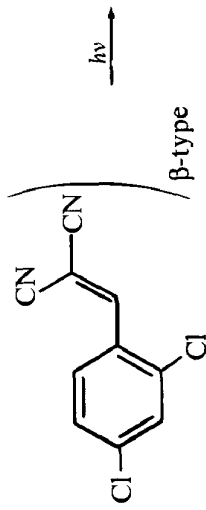

8
$\frac{0}{3}$
$\frac{0}{3}$
$\frac{0}{0}$

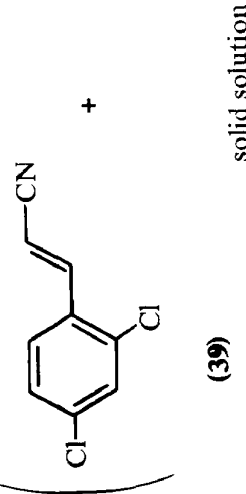

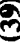

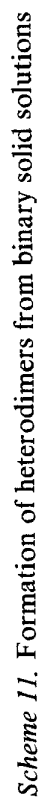

671 


\section{G. M. 'J. SCHMIDT}

Krönert ${ }^{68}$ has reported dimerization of neat ethyl cinnamate to the ethyl ester of $\alpha$-truxillic acid to the extent of approximately two per cent; his data indicate a definite wavelength effect of dimerization versus polymerization. The poor yield of photodimer from unsensitized (neat) ethyl cinnamate contrasts with the formation of non-volatile, predominantly dimeric products from ethyl cinnamate in the presence of sensitizers ( $p$-nitroaniline, picramide $)^{69}$. No attempts were made to separate or characterize the 'dimers'. The authors observed an isosbestic point at $248 \mathrm{~nm}$ in spectra of dilute methanolic solutions of ethyl cinnamate irradiated in the $274 \mathrm{~nm}$ region; this they interpreted as characteristic of the trans $\leftrightharpoons$ cis equilibrium. On the other hand, they state that very little permanent trans $\leftrightharpoons$ cis isomerization occurred in the sensitized undiluted systems. Whilst the dimerization of cinnamic esters proceeds only to an insignificant extent by direct irradiation, bis-trans-cinnamimide (43) in 1,2-dimethoxyethane yielded 48 per cent of $\beta$-truxinimide (44) and a mixture of trans- and cis-cinnamides by irradiation through Pyrex ${ }^{70}$ (Scheme 12).

The very limited evidence so far available suggests that in cinnamic acid itself the singlet state is too shortlived for dimerization to occur in the liquid phase though dicinnamoyl derivatives such as (43) can dimerize. In the esters sensitization probably leads to dimers.

The quantum yield of the photodimerization of cinnamic acid in the solid state has been determined by Rennert et al..$^{71}$ to be 0.7 for light of $\lambda=302 \mathrm{~nm}$; no difference was found in the photosensitivity of the $\alpha$ - and $\beta$-modifications of the monomert. The authors concluded that the photoreaction proceeds by the attack of an excited monomer molecule on a ground state molecule, as follows:

$$
\begin{aligned}
& \mathbf{M} \stackrel{h v}{\rightarrow} \mathbf{M}^{*} \\
& \mathbf{M}^{*}+\mathbf{M} \rightarrow \mathbf{M}_{2}
\end{aligned}
$$

The electronic states involved in the photochemical process of cyclodimerization of cinnamic acid and their analogues have been investigated here by means of the mixed-crystal technique. As mentioned earlier the amides of variously substituted cinnamic acids could be pairwise cocrystallized from the melt, and the mixture irradiated to give the two homodimers and one heterodimer, all three compounds belonging to the $\alpha$-truxillamide type. Pairs of amides were now chosen such that the end-absorption of one of the pair fell at longer wavelength than that of the second amide (Figure 8). Irradiation at wavelengths absorbed by both amides gave the two homodimers and the heterodimer; on the other hand, irradiation, at the long wavelength end, by light absorbed by one species only, totally inhibited formation of the homodimer of the non-absorbing species: now only the homodimer of the longer-wavelength absorbing amide was found together with the heterodimer.

\footnotetext{
$\dagger$ The authors state that Schmidt's prediction ${ }^{18}$ that the $\alpha$-material should be more photosensitive than the $\beta$ was not borne out by their work. No such prediction was made; the statement ${ }^{18}$ that "concerning the yield of these dimerization reactions it is clear that the $\alpha$-and $\beta$-types differ in the theoretical maximum possible conversion into dimer' obviously does not refer to quantum but rather to chemical yield.
} 
PHOTODIMERIZATION IN THE SOLID STATE
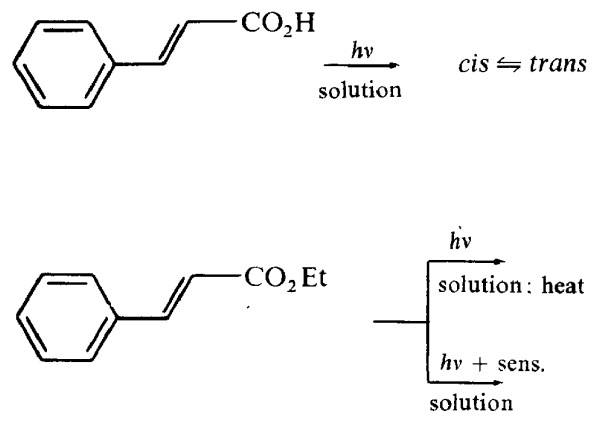

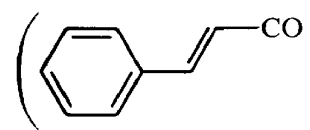

(43)

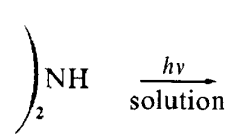

$\int_{2}$

nert.

(1) H. Kröne

(2) H. G. Crume, C. C. Natale and D. J. Kelley.

(3) R. T. LaLonde and C. B. Davies.

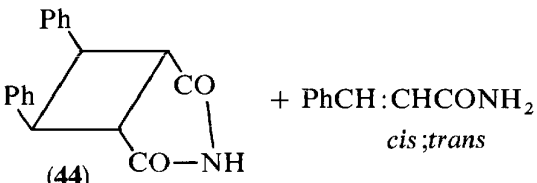

$48 \%$

Scheme 12. Solution photochemistry of some cinnamic acid derivatives

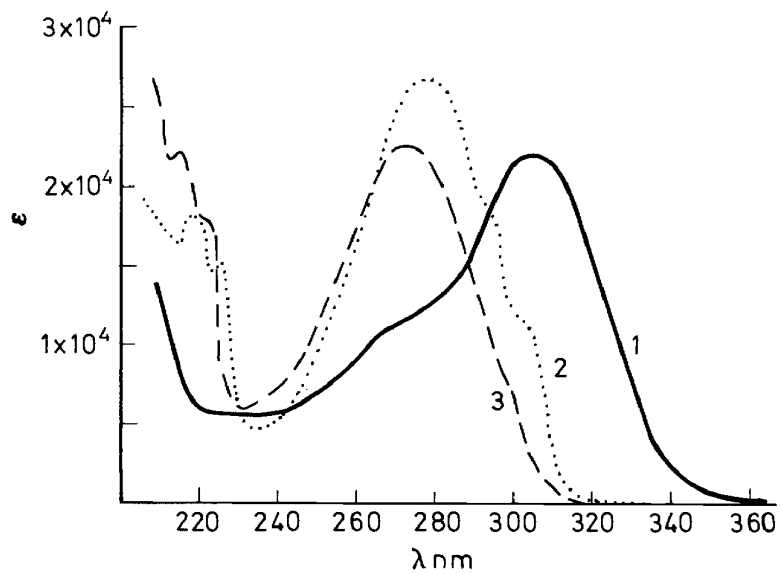

Figure 8. Absorption spectra of $\alpha, \beta$ unsaturated amides $\left(2 \times 10^{-5} \mathrm{M}\right.$ in ethanol): (1) thienylacrylamide, (2) $p$-chlorocinnamide, (3) cinnamide 


\section{G. M. J. SCHMIDT}

The reaction can to a first approximation be described as follows ${ }^{72}$ :

$$
\begin{aligned}
& \text { A } \stackrel{h b}{\rightarrow} A^{*} \quad \text { B } \stackrel{h n}{\rightarrow} B^{*} \\
& \text { for unfiltered light } \quad A^{*}+A \rightarrow A_{2} \quad B^{*}+B \rightarrow B_{2} \\
& \mathrm{~A}^{*}+\mathrm{B} \rightarrow \mathrm{AB} \quad \mathrm{B}^{*}+\mathrm{A} \rightarrow \mathrm{AB} \\
& \text { for filtered light } \\
& \begin{array}{l}
\text { B } \stackrel{h y}{\rightarrow} B^{*} \\
\mathbf{B}^{*}+\mathrm{A} \rightarrow \mathrm{AB} \\
\mathrm{B}^{*}+\mathrm{B} \rightarrow \mathrm{B}_{2}
\end{array}
\end{aligned}
$$

Since the ${ }^{1} A$ level is higher than ${ }^{1} B$ energy transfer from ${ }^{1} B$ to ${ }^{1} A$ is not expected. On the other hand, energy transfer ${ }^{1} A+{ }^{0} B \rightarrow{ }^{0} A+{ }^{1} B$ which could take place in the experiment with unfiltered light, could quench either of the two processes:

$$
\begin{aligned}
& { }^{1} A \rightarrow \text { dimer } \\
& { }^{1} A \rightarrow{ }^{3} A \rightarrow \text { dimer }
\end{aligned}
$$

There is no experimental evidence that incorporation of $B$ into the lattice of $A$ affects the formation of $A_{2}$ : energy transfer in the singlet state seems improbable.

If the photoreactive state derives from the triplet ${ }^{3} A$ or ${ }^{3} B$, then energy transfer in the triplet states

$$
\begin{aligned}
& { }^{3} B+{ }^{0} A \rightarrow{ }^{3} A+{ }^{0} B \\
& { }^{3} A+{ }^{0} B \rightarrow{ }^{0} A+{ }^{3} B
\end{aligned}
$$

depending upon the relative triplet energy levels is ruled out by a similar argument, namely the absence of the homodimer in the filtered, and the absence of quenching in the unfiltered, experiment.

These qualitative arguments leave us with two possibilities. The reaction may proceed from the singlet excited state at a rate faster than that of energy transfer; alternatively, the reaction proceeds from the triplet state with intersystem crossing faster than singlet energy transfer and with reaction faster than triplet energy transfer. In either case the reaction would occur near the site of light absorption.

Since excitation of $B$ leads to $B_{2}$ and $A B$ only and energy is not transferred from $B$ to $A$ the only photochemical path to $A B$ is via

$$
\mathrm{B}^{*}+\mathrm{A} \rightarrow \mathrm{AB}
$$

that is, the combination of an excited with a ground-state molecule, a conclusion which bears out the result derived from the quantum yield measurements quoted above.

The solution photochemistry of the chalcones has been investigated systematically; there is evidence that these ketones can undergo dimerization, isomerization and other reactions. Dr Luwisch ${ }^{20}$ has shown in this Laboratory that, while dimerization in the solid state follows the topochemical rules (see above), the photochemistry is not as clean as that of, say, cinnamic acid; the non-dimeric products have not, however, been investigated.

For the detailed analysis of coumarin photochemistry the original literature must be consulted. We note the general agreement that the cis,syn dimer, 
unlike the trans,syn and trans,anti dimers, is formed from the singlet excited state $^{73,74}$. In this connection the observation that the [coumarin, mercuric chloride] complex yields the cis,syn dimer is of interest; one wonders which excited state of coumarin is involved in the solid medium mainly composed of heavy atoms likely (in solution) to promote intersystem crossing.

The photochemistry of thymine and other pyrimidines has been studied in some detail ${ }^{75,76}$. Triplet dimerization in the fluid state has been demonstrated by sensitization and quenching experiments on thymine and derivatives. There is highly suggestive evidence from thymine in frozen aqueous solution (i.e. under conditions where crystalline thymine hydrate is formed which is known to yield cis, syn dimer on irradiation with $\lambda>290 \mathrm{~nm}$ ) that dimerization in the crystalline phase takes place from the singlet state; the less probable alternative, that intersystem crossing to the triplet precedes dimerization, requires the former process to be $10^{4}$ times faster in the crystal than in isolated thymine molecules as well as totally efficient reaction to dimer of the triplet species ${ }^{75}$.

We can only briefly mention the use of the $\mathrm{KBr}$ pellets containing solid monomers for the determination of quantum yields of dimerization in the pyrimidine series ${ }^{76}$. The quantum yields of dimer formation range from 0.1 for 3-methylthymine to 0.4 for 1 -methylthymine and 0.45 for orotic acid; the authors suggest that a relationship might exist between effective rate of reaction and geometry of the crystal lattice, i.e. that with increasing separation between $>\mathrm{C}=\mathrm{C}<$ bonds the value of the quantum yield falls off. We feel that a word of caution is needed here: the crystallography of pyrimidines (including the monohydrates of thymine and of methylthymine) is complex, and it is more than doubtful whether the crystalline species in $\mathrm{KBr}$ pellets are those crystal forms on which the geometrical arguments are based. It seems likely that the preparation of the pellets introduces into the crystalline material a higher than normal dislocation density, and that it is the quantum yield in such stressed materials which is reported, rather than that of the normal crystal lattice. It is also doubtful whether the monohydrate of thymine is stable under condition of pellet formation.

We summarize the information on the electronic states involved in solid-state dimerization with the generalization that in the majority of cases the reaction proceeds from the first singlet state. The benzalacetophenones (chalcones) as aromatic ketones likely to have a high probability of intersystem crossing to the triplet state, may be a genuine exception; it is tempting to speculate that the more complex photochemistry of solid chalcones is connected with longer lifetimes of the triplet as compared with the singlet states.

We may reasonably assume, in the light of all that has been said so far about solid-state cyclodimerization, that reaction between excited monomer and its ground-state neighbour takes place with the minimum of molecular motion. Consequently, it should be possible to consider the variation of energy with the reaction coordinate such as the continuously decreasing intermolecular separation of the two monomer molecules.

Lamola and Eisinger ${ }^{77}$ have suggested that this path can be divided into three steps, apart from a fourth in which monomers are separated by more 
than $5 \AA$ and emit absorbed energy from the singlet excited state by monomer fluorescence. The excitonic region somewhere near $3 \AA$ can be reached in experiments in which the dimer is imbedded in a rigid glass and then photodissociated; the two monomer units formed are held in parallel or nearparallel separation estimated to be $2.8 \AA$ (for dimethylthymine) from the exciton splitting of the absorption spectrum. These monomer pairs which show no fluorescence, are redimerized with a quantum yield of unity. The authors suggest that this state is an intermediate in the dimerization of thymine in the crystalline state and propose to connect the (lower) exciton state with the excimer state 'so that the latter is most likely an intermediate in the photodimerization'.

In my opinion there is yet inadequate evidence for the hypothesis that the excimer state is an intermediate in the sequence of non-radiative relaxation steps connecting the monomer in its excited state with the chemical product in its ground state, at least that excimer state which is currently defined as the species that emits unstructured fluorescence red-shifted with respect to monomer emission.

Pending elucidation of the energy surface over which the two molecules move, we may look for information on the changes in molecular structure during the course of the reaction. Thus, whilst there is little nuclear reorganization of cyclic monomers such as pyrimidines, coumarins, etc. during cyclodimerization, some changes in molecular conformation obviously must occur in the reaction of open-chain systems.

We know from the position of the fluorescence emission that, in the majority of organic molecules, the change in their nuclear configuration during the interval between absorption and re-emission is small; major re-organization must begin during the motion of the two molecules towards each other, that is during the rehybridization $\left(s p^{2} \rightarrow s p^{3}\right)$ of the four reacting centres at distances which permit partial bond formation but also imply repulsion between the substituent groups of the four centres. Such repulsion sets in at the latest at $2.8 \AA$ so that at this separation of the reacting atoms the molecule is almost certainly no longer planar.

I suggest that a study of the molecular deformation which takes place as the molecules move towards each other, can throw light on the type of molecular interaction which is responsible for the passage via the first singlet-ground-state pair to the dimer. I believe further that this study is by no means as impossible as it appears at first sight. I am thinking in particular of reactions in chiral crystal structures where dimerization within the molecular stack of twisted and hence prochiral monomer units may proceed in a preferred direction leading to chiral product; in other words, front-side and rear-side attack of the excited molecule on the prochiral ground-state molecule (that is: attack on the upper or lower partner in the translation stack) may have sufficiently different probability to generate excess of one or the other enantiomer. Several variants of this experiment are possible and being investigated in our Laboratory. Determination of $x$-ray methods of the absolute configuration of one of the crystals and of the product generated in excess from this enantiomer will permit a still more detailed description of the reaction course. 


\section{ACKNOWLEDGEMENTS}

The solid-state chemistry group of the Department of Chemistry gratefully acknowledges financial support by the National Bureau of Standards, Washington, D.C. and by the Stiftung Volkswagen. The author thanks Mrs T. Schwarz for help in the preparation of the manuscript.

\section{REFERENCES}

1 W. Marckwald, Z. Phys. Chem. 30, 140 (1899).

${ }^{2}$ G. Ciamician and P. Silber, Ber. Dtsch. Chem. Ges. 34, 2040 (1901).

${ }^{3}$ H. Stobbe and F. K. Steinberger, Ber. Dtsch. Chem. Ges. 55, 2225 (1922).

4 A. W. K. de Jong, Ber. Dtsch. Chem. Ges. 56, 818 (1923).

5 A. Senier and F. G. Shephard, J. Chem. Soc. 95, 1943 (1909).

${ }^{6}$ For summary of the results of this phase see $\mathrm{H}$. Bacher, in Handbücher der biologischen Arbeitsmethoden, Abt. I, Teil 2, II, 1, p 1829. Ed. Abderhalden, Urban and Schwarzenberg. Springer: Berlin-Vienna (1929).

7 P. Groth, Chemische Krystallographie, W. Engelmann: Leipzig (1917).

8 For summary see G. M. J. Schmidt, 'The photochemistry of the solid state'. Contribution to the $13^{\mathrm{e}}$ Conseil de Chimie de 1'Institut International de Chimie (Bruxelles 1965), which appeared in condensed form in Reactivity of the Photoexcited Organic Molecule, Interscience: London (1967).

9 M. D. Cohen, Mol. Cryst. Liquid Cryst. 9, 287 (1969).

10 D. P. Craig and S. Sarti-Fantoni, Chem. Commun. 742 (1966).

11 J. M. Thomas and J. O. Williams, Chem. Commun. 432 (1967).

12 M. D. Cohen, I. Ron, G. M. J. Schmidt and J. M. Thomas, Nature, London, 224, 167 (1969).

13 D. P. Craig, R. Mason, P. Pauling and D. P. Santry, Proc. Roy. Soc. A, 286, 98 (1965).

14 D. E. Williams, J. Chem. Phys. 45, 3770 (1966);

D. E. Williams, Acta Cryst. A25, 464 (1969).

15 L. Leiserowitz and G. M. J. Schmidt, J. Chem. Soc. A, 2372 (1969).

16 B. S. Green and G. M. J. Schmidt, to be published.

17 e.g. M. A. El Sayed, M. T. Wauk and G. W. Robinson, Molec. Phys. 5, 205 (1962).

${ }^{18}$ G. M. J. Schmidt, J. Chem. Soc. 2014 (1964).

19 M. Lahav and G. M. J. Schmidt, J. Chem. Soc. B, 239 (1967).

20 M. Luwisch, Ph.D. Thesis, Weizmann Institute of Science: Rehovot (1968).

21 F. I. Sonntag and G. M. J. Schmidt, unpublished results.

22 R. Goldstein, Ph.D. Thesis, Weizmann Institute of Science: Rehovot (1967).

23 D. Rabinovich and G. M. J. Schmidt, J. Chem. Soc. B, 144 (1967).

24 G. W. Griffin, A. F. Vellturo and K. Furukawa, J. Amer. Chem. Soc. 83, 2725 (1961).

25 T. Sadeh and G. M. J. Schmidt, J. Amer. Chem. Soc. 84, 3970 (1962).

26 M. Lahav and G. M. J. Schmidt, J. Chem. Soc. B, 312 (1967).

27 B. S. Green, M. Lahav and G. M. J. Schmidt, J. Chem. Soc. B, 1552 (1971).

${ }^{28}$ M. D. Cohen, B. S. Green, Z. Ludmer and G. M. J. Schmidt, Chern. Phys. Letters, 7, 486 (1970).

29 B. S. Green, A. Elgavi and G. M. J. Schmidt, unpublished results.

30 J. Bregman, K. Osaki, G. M. J. Schmidt and F. I. Sonntag, J. Chem. Soc. 2021 (1964).

${ }^{31}$ L. Leiserowitz and G. M. J. Schmidt, Acta Cryst. 18, 1058 (1965).

32 B. S. Green, unpublished results.

${ }^{33}$ W. Drenth and E. H. Wiebenga, Acta Cryst. 8, 755 (1955).

${ }^{34}$ I. Ron and G. M. J. Schmidt, to be published.

${ }^{35}$ M. Gorodetzky and Y. Mazur, J. Amer. Chem. Soc. 90, 6540 (1968).

36 J. L. R. Williams, in Topics in Current Chemistry, 13, 227 (1969).

${ }^{37}$ F. I. Sonntag and R. Srinivasan, quoted in ref. 36.

$38 \mathrm{~S}$. Kikuchi and $\mathrm{K}$. Nakamura, quoted in ref. 36.

39 E. Heller, Ph.D. Thesis, Weizmann Institute of Science: Rehovot (1969).

40 J. C. J. Bart and G. M. J. Schmidt, to be published.

41 M. D. Cohen, Z. Ludmer, J. M. Thomas and J. O. Williams, Chem. Commun. 1172 (1969).

42 K. S. Wei and R. Livingston, J. Chem. Phys. 71, 548 (1967).

R. Livingston and K. S. Wei, J. Chem. Phys. 71, 541 (1967).

43 A. Chapiro and G. Lozach, C.R. Acad. Sci., Paris, Sér. C, 267, 37 (1968). 
44 D. O. Cowan and R. L. Drisko, J. Amer. Chem. Soc. 89, 3068 (1967).

45 G. W. Griffin, J. E. Basinski and A. F. Vellturo, Tetrahedron Letters, No. 3, 13 (1960);

G. W. Griffin, U.S. Pat. No. 3139395 to American Cynamid Co. (30 June 1964).

46 R. E. Marsh, E. Ubell and H. E. Wilcox, Acta Cryst. 15, 35 (1962).

47 Ju. T. Struchkov, A. J. Kitaigorodskii and T. L. Khotsyanova, Dokl. Akad. Nauk SSSR, 93, 675 (1953).

48 D. Rabinovich and G. M. J. Schmidt, unpublished results.

49 W. Nieuwenkamp and J. M. Bijvoet, Z. Kristallogr. 84, 49 (1932).

50 S. E. Filippakis, L. Leiserowitz and G. M. J. Schmidt, J. Chem. Soc. B, 297 (1967).

51 S. E. Filippakis, L. Leiserowitz and G. M. J. Schmidt, J. Chem. Soc. B, 290 (1967).

52 H. P. Kaufmann and A. K. Sen Gupta, Liebigs. Ann. Chem. 681, 39 (1965).

53 W. D. Closson, S. F. Brady, E. M. Kosower and P. C. Huang, J. Org. Chem. 28, 1161 (1963).

${ }^{54}$ S. E. Filippakis, L. Leiserowitz and G. M. J. Schmidt, J. Chem. Soc. B, 305 (1967).

${ }^{55}$ M. Lahav and G. M. J. Schmidt, Tetrahedron Letters, 2957 (1966).

56 W. L. Dilling, Chem. Rev. 69, 845 (1969).

${ }^{57}$ H. Stobbe and E. Färber, Ber. Dtsch. Chem. Ges. 58, 1548 (1925).

58 R. C. Cookson, D. A. Cox and J. Hudec, J. Chem. Soc. 4499 (1961).

59 H. Midorikawa, Bull. Chem. Soc. Japan, 26, 302 (1953).

60 J. Corse, B. J. Finkle and R. E. Lundin, Tetrahedron Letters, 1 (1961).

61 B. S. Green and G. M. J. Schmidt, Tetrahedron Letters, 4249 (1970).

62 N. E. Rowland, F. Sondheimer, G. A. Bullok, E. LeGoff and K. Grohmann, Tetrahedron Letters 4769 (1970).

${ }^{63}$ M. Hasegawa, F. Suzuki, H. Nakamishi and Y. Suzuki, Polymer Letters, 6, 293 (1968).

${ }^{64}$ M. Hasegawa and Y. Suzuki, Polymer Letters, 5, 815 (1967).

${ }^{65}$ M. Iguchi, H. Nakamishi and M. Hasegawa, J. Polym. Sci. A, 6, 1055 (1968).

66 D.-J. Hung, M.Sc. Thesis, Weizmann Institute of Science: Rehovot (1969).

67 M. Tsudas, J. Soc. Sci. Phot. Japan, 28, 7 (1965).

68 H. Krönert, Ph.D. Thesis, Technische Universität: Berlin (1967).

69 H. G. Curme, C. C. Natale and D. J. Kelley, J. Phys. Chem. 71, 767 (1957).

70 R. T. LaLonde and C. B. Davies, Canad. J. Chem. 47, 3250 (1969).

71 J. Rennert, E. M. Ruggiero and J. Raff, Photochem. Photobiol. 6, 29 (1967).

72 P. N. Nie, M.Sc. Thesis, Weizmann Institute of Science: Rehovot (1969).

73 G. S. Hammond, C. A. Stout and A. A. Lamola, J. Amer. Chem. Soc. 86, 3103 (1964).

${ }^{74}$ H. Morrison, H. Curtis and T. McDowell, J. Amer. Chem. Soc. 88, 5415 (1966).

75 A. A. Lamola, Photochem. Photobiol. 7, 619 (1968).

76 R. Lisenski and K. L. Wierzchowski, Photochem. Photobiol. 11, 327 (1970).

77 A. A. Lamola and J. Eisinger, Proc. Nat. Acad. Sci., Wash. 59, 46 (1958).

\section{OBITUARY}

Professor Gerhard M. J. Schmidt died in Zurich on 12 July 1971, aged 51, where, characteristically, he was delivering a series of lectures in spite of his illness; from there he was planning to travel to the XXIII IUPAC Congress in Boston where he was to have chaired a Photochemistry section.

Professor Schmidt was at home both in pure scientific research and in the application of that research, bringing dynamic imagination and dedication to both. His unique approach to solid-state chemical reactions, reflected so well in the present contribution on Solid State Photodimerization, was based on his conviction that the results obtained from a combination of the disciplines of organic chemistry, crystallography, and spectroscopy were important for the intimate understanding of the factors governing chemical reactivity. He further believed that an understanding of the behaviour of crystalline systems would help elucidate the role of short-range and long-range order in highly organized biological systems as well.

His death, at the peak of his active investigation into problems such as organic photochemistry, high-pressure reactions, heterogeneous catalysis, gas-solid, liquidsolid, and solid-solid chemical reactions, systematics of molecular packing in crystals, spectroscopy in organic crystals, and asymmetric synthesis, is a major blow. The loss of his incisive and original contributions will be deeply felt both by his immediate co-workers in these areas and by the international scientific community. 